\title{
Pullout Test on Fully Grouted Bolt Sheathed by Different Length of Segmented Steel Tubes
}

\author{
Xiaowei Feng, Nong Zhang, Guichen Li, and Gangye Guo \\ Key Laboratory of Deep Coal Resource Mining, Ministry of Education of China, School of Mines, \\ China University of Mining and Technology, Xuzhou 221116, China
}

Correspondence should be addressed to Nong Zhang; zhangnong@126.com

Received 25 October 2016; Revised 28 December 2016; Accepted 11 January 2017; Published 20 February 2017

Academic Editor: Tai Thai

Copyright (C) 2017 Xiaowei Feng et al. This is an open access article distributed under the Creative Commons Attribution License, which permits unrestricted use, distribution, and reproduction in any medium, provided the original work is properly cited.

In order to evaluate the anchorage performance of rebar bolt sheathed by different length of segmented steel tubes, a total of eight groups of pullout tests were conducted in this study. The steel tubes, segmented by $5 \mathrm{~cm}, 7 \mathrm{~cm}, 9 \mathrm{~cm}, 10 \mathrm{~cm}$, and $15 \mathrm{~cm}$, utilized in current study were bonded together by a high performance two-component adhesive to form standard $30 \mathrm{~cm}$ long steel tube. Unlike axial stress distribution in bolt, the axial stress distribution in steel tube showed exponential decrease trend from tube-clamp end to bolt-clamp end; thus a series of interesting results were observed. For instance, the sequence for segments detachment had its specific order of priority; the failure form of bolting system, the load oscillation characteristics, and the final displacement were highly determined by the length of the last segment, namely, the one fixed by clamp of testing machine. Moreover, the loaddisplacement relationship for some particular samples was further investigated from the perspective of energy transformation, and the disequilibrium extension of interfacial decoupling was also discussed. This paper, from a relatively idealized perspective, presents a laboratorial solution to interpret the mechanical performance of the bolt installed in layered strata; so far at least it demonstrates that a bolt installed in comparatively thicker layer of strata can last more durable and stable.

\section{Introduction}

Among dozens of supporting components utilized in underground mining or construction activities around the world, the rock bolt is one of the most popular devices on account of its series of superiorities, such as active support effects on rock surface, versatile applicability for different kinds of geological conditions, relatively low cost, convenient and fast installation, and so forth. After over one hundred years of step-by-step advancement and development of this technology since the end of 19th century, rock bolt now has many derived species like bonded bolt, Swellex, the Split Set, the Expansion Shell, the cone bolt, Garford, Roofex, and the Dbolt. However, most of them only show minor differences with each other in their design and they almost share the same theoretical background, like mechanically anchored bolts, fully/partially grouted bolts, and friction anchored bolts.

Generally, the fully grouted bolt using resin cartridges is mostly utilized worldwide $[1,2]$. In the U.S. roof bolting has been the primary roof support method for underground coal mines since the early 1970 s [3]; more than $90 \%$ of the approximately 68 million roof bolts installed annually in underground coal mines in the USA belong to this kind of bolt [4]. As compared with end-anchored one or friction anchored one, the performance of fully grouted bolt is much more reliable and it can provide a full-range support to rock mass all through its length [5]. But the performance also depended on a series of important factors, such as the bonding properties of bolt/grout interface, or grout/rock interface, the mechanical properties of bolt rod and external faceplate (if installed), strength of grouting material, and properties of rock mass, pretensioned or nonpretensioned.

Unlike other support methods adopted in underground operations, rock bolt is installed within the rock mass to provide reinforcement effects from interior, whereas structures such as U-shaped steel, steel net, and hydraulic prop passively restrain the deformation of rock mass on the tunnel perimeter. This is also a distinction between reinforcement and support according to Windsor and Thompson's literature [6]. Hence it may be difficult to probe load-deformation 


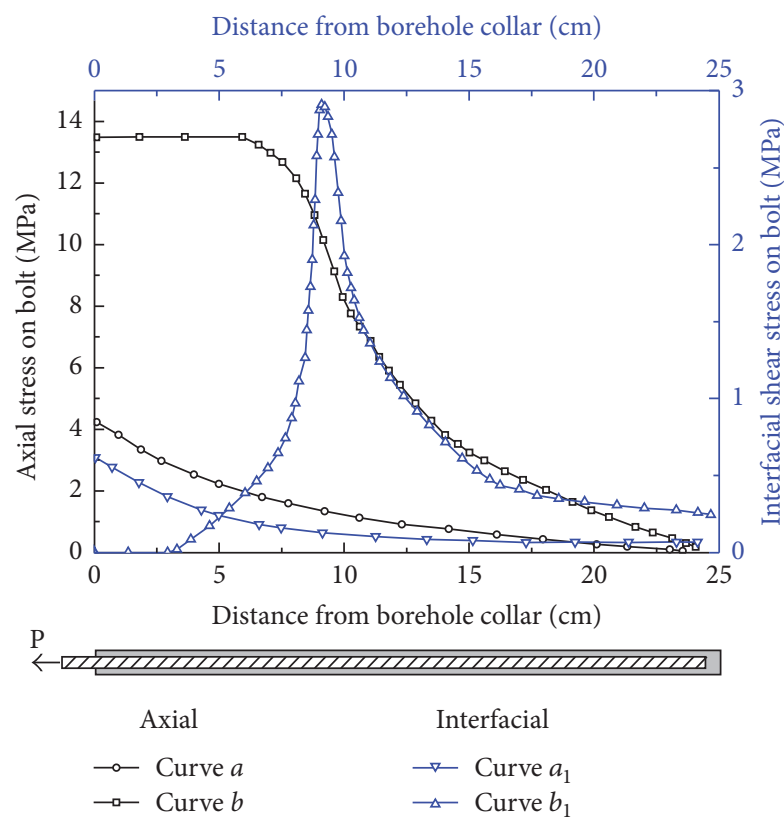

(a)

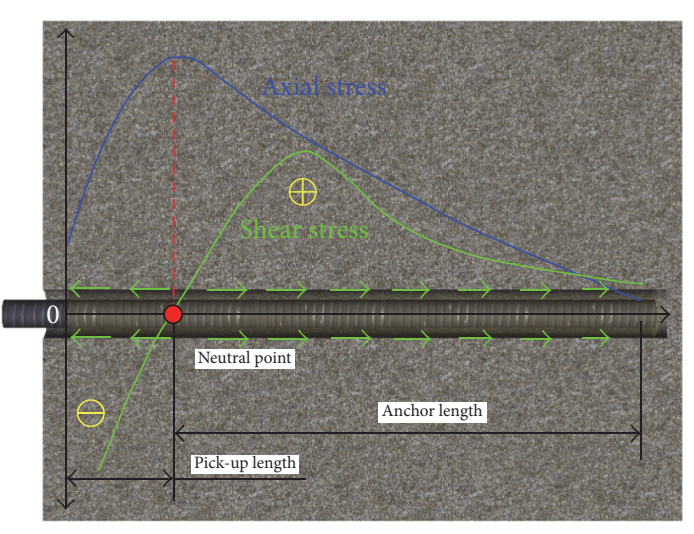

(b)

FIGURE 1: Comparison between axial stress and shear stress distribution along a rock bolt in pullout test and in situ. (a) Distribution patterns for axial stress and interfacial shear stress of rock bolt under pullout test (after Hawkes and Evans [14]); (b) distribution of axial stress and interfacial shear stress for rock bolt in situ (adapted from Farmer's work [7]).

mechanism in engineering field because of multivariate factors. Generally, laboratory pullout test is utilized to investigate the reinforcement effects of bolts. Regardless of the great number of pullout tests conducted around the world in various types [7-13], certain mechanical differences between bolt in pullout test and bolt in situ should be noted.

\section{Mechanical Differences between Bolt in Pullout Test and Bolt In Situ}

For a fully grouted bolt embedded in steel tube and then subjected tensile load in pullout test, Framer's solution predicts that both of the axial stress of bolt and the interfacial bonding stress will drop exponentially from the loading end to the free-loading end [7]. Typical pullout test results conducted by Hawkes and Evans are plotted in Figure 1(a) [14]; curves $a$ and $b$ show two different states of axial stress along the bolt when suffering tensile load. $a$ indicates a coupling interfacial state that the bolt is under a relatively low pullout load; $b$ indicates a partially decoupled interfacial state which is caused by overlarge pullout load. As for the shear stress distribution pattern along the bonding interface, there has been certain correspondence with the axial stress distribution pattern hereinbefore shown. Curves $a_{1}$ and $b_{1}$ in Figure 1(a) show the interfacial stress distribution mode; the former indicates a case that the pullout load is relatively low, whereas the latter indicates a case that the overlarge pullout load leads to certain amount of interfacial bonding failure. It has been completely testified that the peak bonding shear stress will gradually move from loading end to the free-loading end for a bolt subjected tensile load [10]; then a complete bonding failure should firstly occur at a section close to the loading end, causing a zero shear stress at the beginning of curve $b_{1}$, which is then followed by certain range of partial bonding failure towards the peak stress point. Beyond the section, the shear stress decreases exponentially to the free-loading end in accordance with Farmer's solution [7].

For an in situ installed rock bolt, however, some particular differences should be addressed. Figure 1(b) shows axial/shear stress distribution along a rock bolt installed in situ; it can be seen that distribution patterns of both axial stress and shear stress show obvious differences with what Figure 1(a) presents. However, for the section close to the borehole end, the axial stress exhibits similar trend to that in pullout test. The explanation for these differences mainly lies in the fact that the bolt in pullout test only has an anchoring length whereas the bolt in situ has another pick-up length and neutral point.

\section{Scope and Theoretical Background of This Study}

Due to the millions of years' strata sedimentary on earth, many strata in deep coal mines show laminated occurrence. Bolt installed in this kind of strata should be able to sustain severe disturbance of serial decoupling along the bonding interface or strata separation; it may be difficult to directly conduct real-time monitoring on bolting failure process and evaluate relevant bearing capacity in practical engineering sites. Here in this study, we design an experimental setup which we hope to present certain contributions to corresponding underground supporting theories. A total of eight 


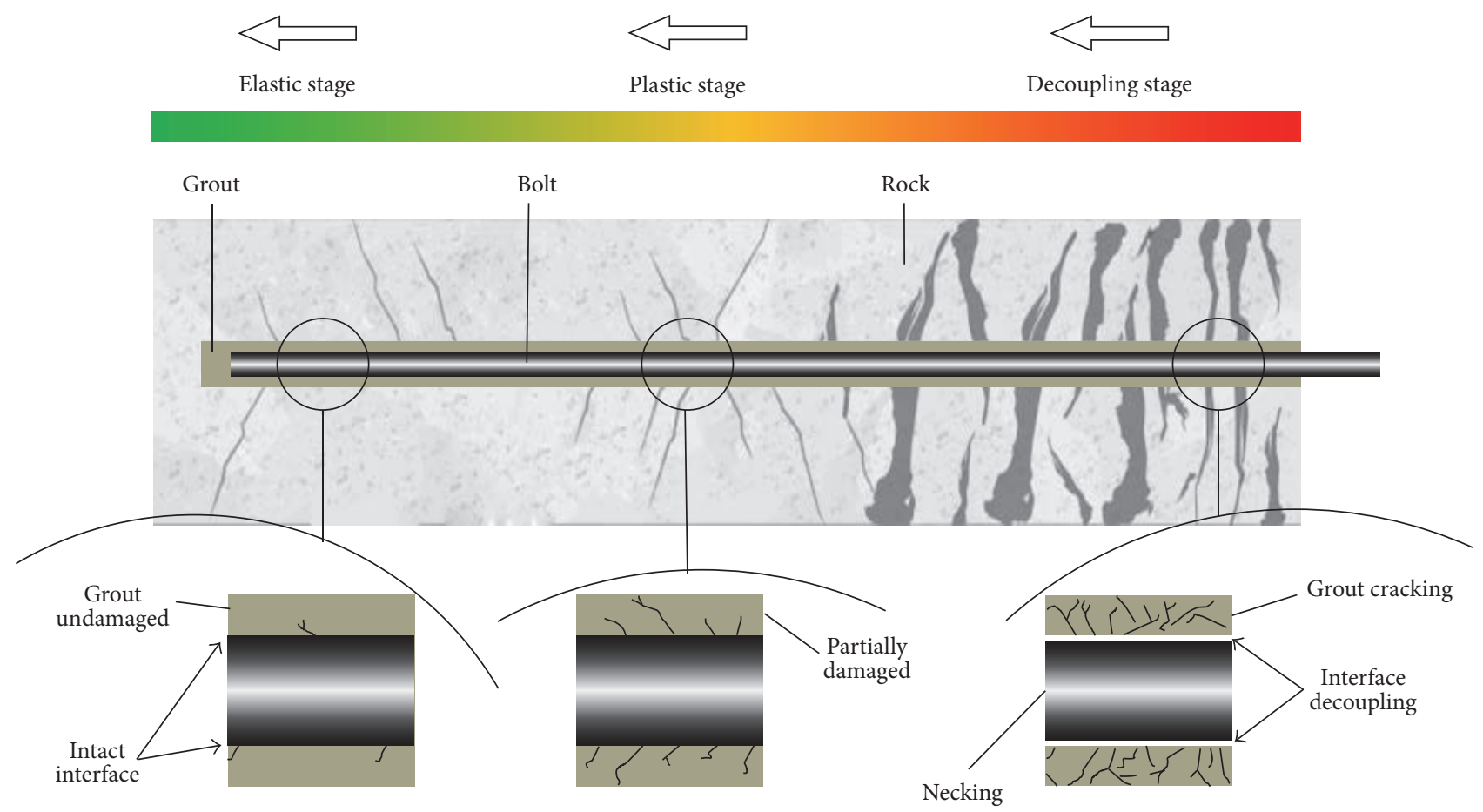

FIGURE 2: Description for failure process of a passively installed rock bolt under pullout load.

groups of pullout tests on fully grouted bolt embedded in segmented steel tubes were conducted. The segmented steel tubes, varied by length as $5 \mathrm{~cm}, 7 \mathrm{~cm}, 9 \mathrm{~cm}, 10 \mathrm{~cm}$, and $15 \mathrm{~cm}$, utilized in current study were bonded together by a high performance two-component adhesive to form standard $30 \mathrm{~cm}$ long steel tube. Before we conduct the experiment, some notable theoretical tips need to be proposed firstly for clarification.

For a passively installed rock bolt, the "passive" means no pretension force was applied on the bolt-exposed end during bolt installation process, and its support effects will be only activated provided that the rock mass deforms firstly [15]. Generally, its final failure is caused by decoupling of bolt/grout interface or grout/rock interface if the bolt tensile fracture is excluded, depending on which one is the weakest [16]. This failure process progressively extends from loaded end (borehole collar) to unloaded end (borehole bottom) and finally leads to the total failure of bolting system; Figure 2 schematically describes the specific mechanism under pullout load, which is similar to the situation in laboratorial test. Three different kinds of stages, decoupling stage, plastic stage, and elastic stage, are observed from loaded end (exposed end) to unloaded end (embedded end) in sequence. The elastic range is decreasing whereas the decoupling range is increasing under ascending pullout load, whereas the plastic range plays a transitional role which alters a specific elastic section into a decoupling section, and plastic range generally keeps an approximately fixed length under an idealized theoretical situation. The peak shear stress during this process is associated with elastic stage; its moving pace keeps identical as that of elastic range. Actually, many literatures have reported this kind of evolution process; for more details, please refer to relevant works [15, 17-19], and so forth.

The mechanical interaction mechanism among steel tube, bonding material, and bolt is drawn in Figure 3; for a specific segment taken from the bolting system, it always keeps axial mechanical equilibrium, which means that the overall resultant force applied on the upper end equals that of the lower end. Hence, the axial stress distribution in steel tube shows a completely opposite pattern as what exists in bolt rod, considering that the axial stress distribution of bolt has already been explained in Section 2; hence axial stress in steel tube shows an exponential increase from bolt-clamp end to tube-clamp end. Based on aforementioned theories, it can be concluded that section nearby the tube-clamp end bears a relatively larger force for steel tube. Due to the fact that the $30 \mathrm{~cm}$ long steel tube is axially bonded by segmented tubes with different lengths, thus the separation of bonded steel tubes subjected to pullout load under laboratorial condition will firstly occur at the bonding ends closing to tube-clamp end; study hereinafter gives specific explanations for varied forms of bolting failures under this experimental setup.

\section{Laboratory Study}

4.1. Samples Preparation Procedure. Layered strata in engineering field can have different thicknesses, and their bed succession also shows an unordered status. In this experiment, steel tubes with varied lengths were utilized to simulate layered strata. In the past study, adopting steel tube to simulate rock mass in laboratory is generally accepted, and 


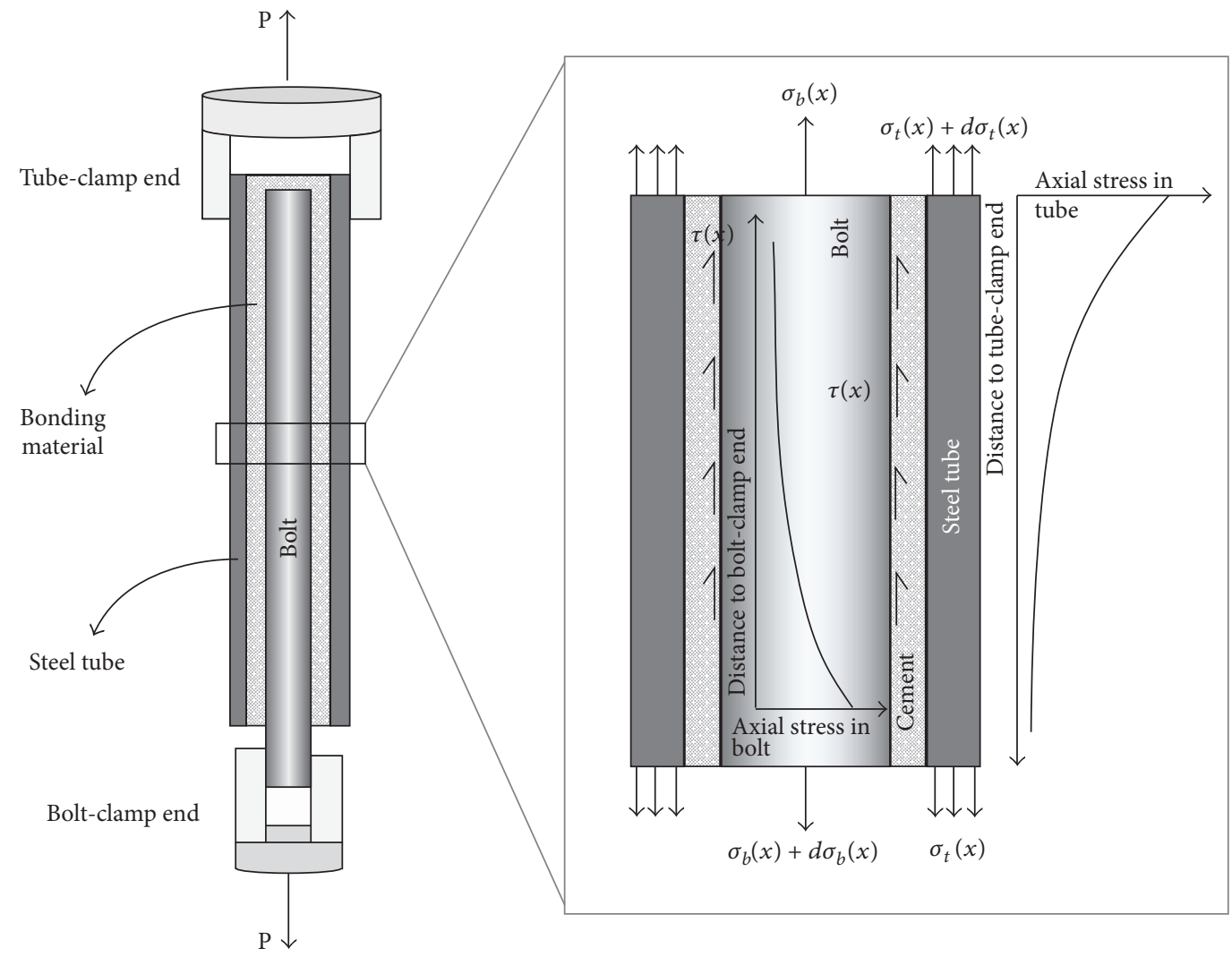

FIgURE 3: Mechanical interaction mechanism of a bolting system.

TABLE 1: Samples grouping and labels specification.

\begin{tabular}{lccc}
\hline Sample labels & Combining forms & Sample labels & Combining forms \\
\hline S1 (S1-1, S1-2, S1-3) & $15+5+5+5^{*}$ & S5 (S5-1, S5-2, S5-3) & $9+7+7+7$ \\
S2 (S2-1, S2-2, S2-3) & $15+5+10$ & S6 (S6-1) & $10+5+15$ \\
S3 (S3-1, S3-2, S3-3) & $15+10+5$ & S7 (S7-1, S7-2) & $10+10+10$ \\
S4 (S4-1, S4-2) & $15+15$ & S8 (S8-1, S8-2) & $10+15+5$ \\
\hline
\end{tabular}

${ }^{*}$ The terms sequence means the order for different lengths of segments from tube-clamp end to bolt-clamp end.

this kind of test measure was also widely adopted in early literatures $[20,21]$. It is surely that this testing measure can evaluate the bearing capacity of a bolting system; a specially designed sample that is able to sustain a large pullout load under laboratorial environment will undoubtedly provide better reinforcement to rock in practical trials.

Generally, each sample was comprised of a rebar rock bolt (35 cm in length and $18 \mathrm{~mm}$ in diameter) and a $30 \mathrm{~cm}$ long steel tube; the steel tube was combined by several steel tube segments. The inner diameter and outer diameter for the segment were $30 \mathrm{~mm}$ and $50 \mathrm{~mm}$, respectively. But their length, intercepted by $7 \mathrm{~cm}, 9 \mathrm{~cm}$, and $10 \mathrm{~cm}$, varied from $5 \mathrm{~cm}$ to $15 \mathrm{~cm}$; then the segments with varied lengths combined with others to make a standard steel tube with a unified length of $30 \mathrm{~cm}$. In accordance with this pattern, a total of 8 forms of steel tubes were finally created, and they are listed in Table 1. For the sake of clarification, we hereinafter define the first segment as the one close to bolt-clamp end, and the last segment is the one clamped by MTS machine. For further clarification, all of these combining forms are schematically drawn in Figure 4(a). The segments were bonded together by a high performance two-component adhesive named Ergo (see Figure 4(b)), which could produce a much better bonding strength on the ends than traditional welding measure. This adhesive has a series of advantages like high viscosity, high strength, and high temperature resistance; its ultimate strength for a metal-to-metal bonding can reach up to $20 \mathrm{~N} / \mathrm{mm}^{2}$, and hence its application in this test is reasonable. In addition, the last segment aligned along the bolting system should avoid being $5 \mathrm{~cm}$ and $7 \mathrm{~cm}$; otherwise the pullout test would cause a premature failure close to the tube-clamp end considering mechanical equilibrium illustrated in Figure 3. For example, a combining form like $15+10+5$ should be avoided.

The grouting material in this test was a special kind of modified cement, which was mainly utilized for fully grouting bolt support in coal mine roadway. The cement, with cement to water ratio predefined as 0.25 , can have a uniaxial 


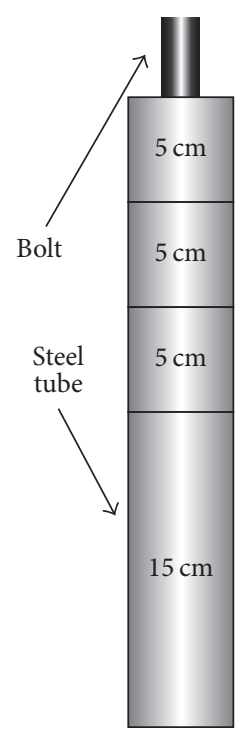

S1

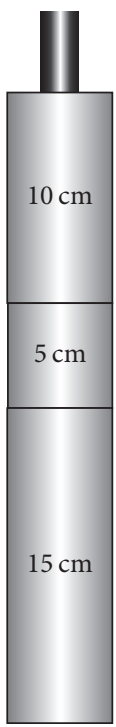

S2

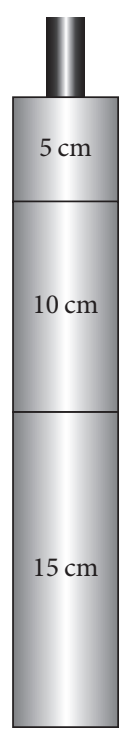

S3

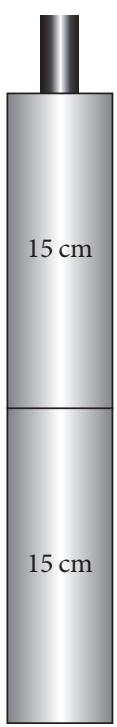

S4

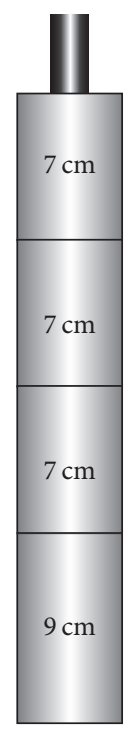

S5

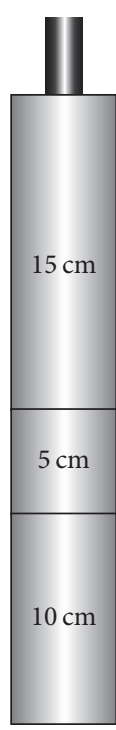

S6

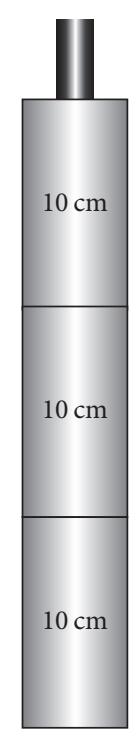

S7

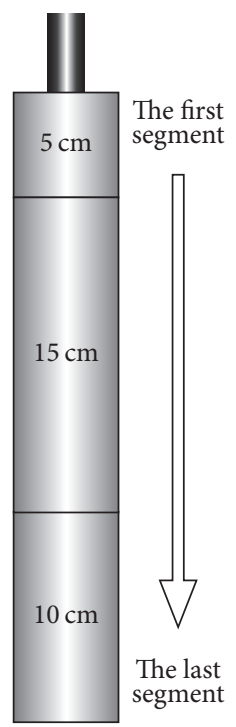

S8

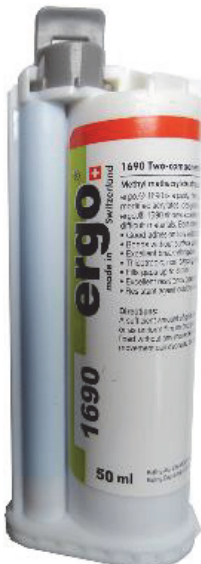

(b)

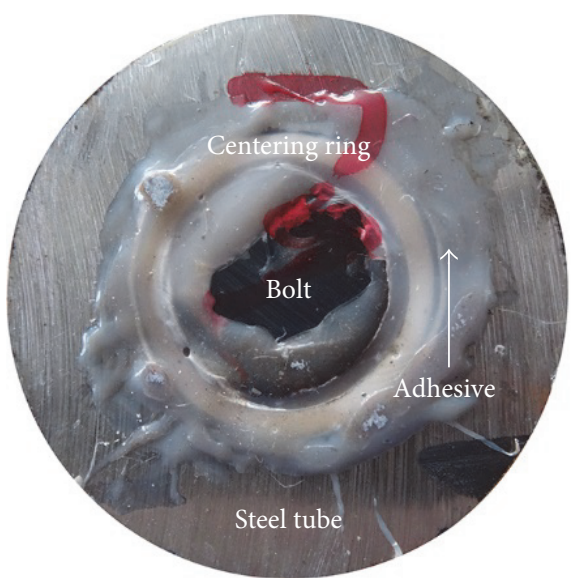

(c)

FIGURE 4: Combining forms for steel tube segments (a), photo of the adhesive utilized in this test to bond different lengths of tube segments (b), and bottom view for prepared specimen (c).

compression strength (UCS) of $3 \mathrm{MPa}$ within 1 hour, $30 \mathrm{MPa}$ within 24 hours, and conservative $70 \mathrm{MPa}$ within 28 days under room temperature. The samples preparation process is described as follows:

(1) Bond the segmented steel tubes together based on combining criterion shown in Figure 4(a), let the bonded segments stand for about six hours under room temperature, and then proceed to the next procedure. Place a centering ring at end of the last segment of steel tube, the inner diameter and outer diameter of the ring equal the diameter of bolt and the inner diameter of steel tube, respectively, and the thickness of the ring is $2 \mathrm{~mm}$. This device can guarantee the coincidence between axis of the bolt and that of the steel tube; it thus avoids potential deviatoric stress during pullout test; note that the deviatoric stress will greatly disturb the accuracy of pullout test and lead to premature failure of bolting system.

(2) Insert the bolt into the end of the semifinished sample prepared by step (1), and align their end faces; then use fast-setting waterproofing adhesive to bond the end of bolt, centering ring, and the end of the steel tube together; this process avoids potential leakage during the follow-up cement grouting procedure. A bottom view showing the bonded combination is presented in Figure 4(c).

(3) Adequately mix the cement and water together under the mass ratio of 0.25 ; then pour the mixture into a $100 \mathrm{~mL}$ injector. Afterwards, keep the sample processed by previous step vertically placed and slowly inject the cement into the annular gap between the bolt and the steel tube; the cement flows downward under the effect of gravity. Stop injection when the 


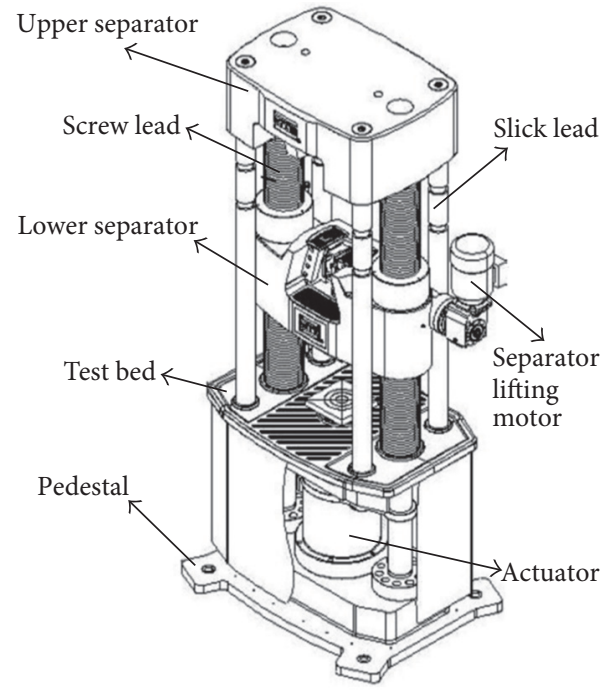

(a)

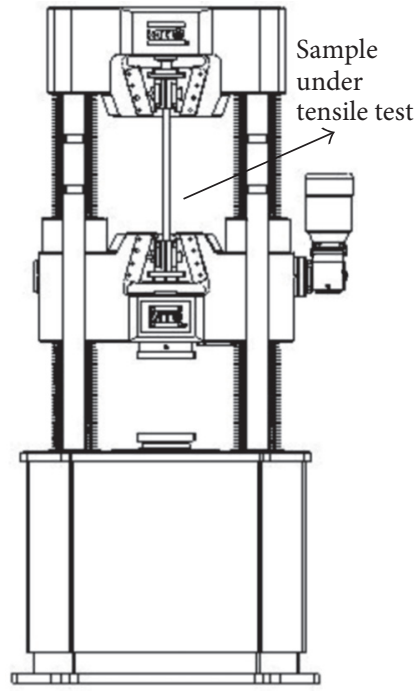

(b)

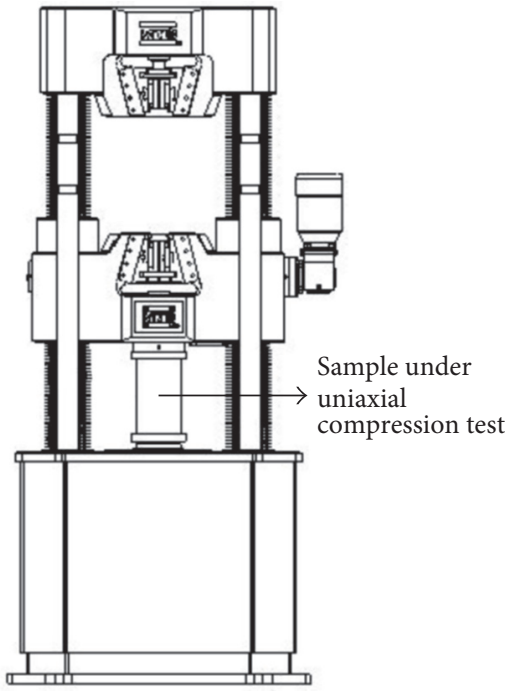

(c)

FIGURE 5: Schematic sketch for the testing machine (a) and its front views for tensile test (b) and compression test (c).

fluid level reaches to the top end of the steel tube; the adoption of injector in this step guarantees a uniform and stable grouting speed of the cement, and thus voids in the cement column surrounding the bolt can be avoided.

(4) Place a similar top centering ring to fill the annular space between bolt and steel tube after the cement paste reaches the upper limit of the steel tube; similarly, the top centering ring can cooperate with the bottom centering ring to insure the coincidence between the axis of bolt and the axis of steel tube.

4.2. Brief Introduction for Test Machine. The tensile test was conducted on a MTS criterion 64 series testing machine; it mainly consists of assembly parts as follows: pedestal, actuator, test bed, lower separator, upper separator, screw lead, and slick lead. The test bed is connected with the upper separator by lead to form a stiff frame, and the test bed is also connected with the actuator by load cell. This machine has two testing spaces; the first one is designed for tensile test locating between the lower separator and the upper separator; the second one is designed for compression test locating between the test bed and the lower separator. Both of the spaces can be adjusted by moving the lower separator. The schematic sketch for the machine is shown in Figure 5.

Here in this test, the bolt-cement-steel bolting system is pulled by the movement of lower separator and upper separator; the bolt-exposed end is fixed by lower clamp whereas the steel tube end is fixed by upper clamp, and then the moving directions for bolt and the tube suffering pullout load are downward and upward, respectively.

\section{Results and Discussion}

5.1. Standard Tensile Test on Bolt. The mechanical property of the bolt under tensile load is vital to subsequent

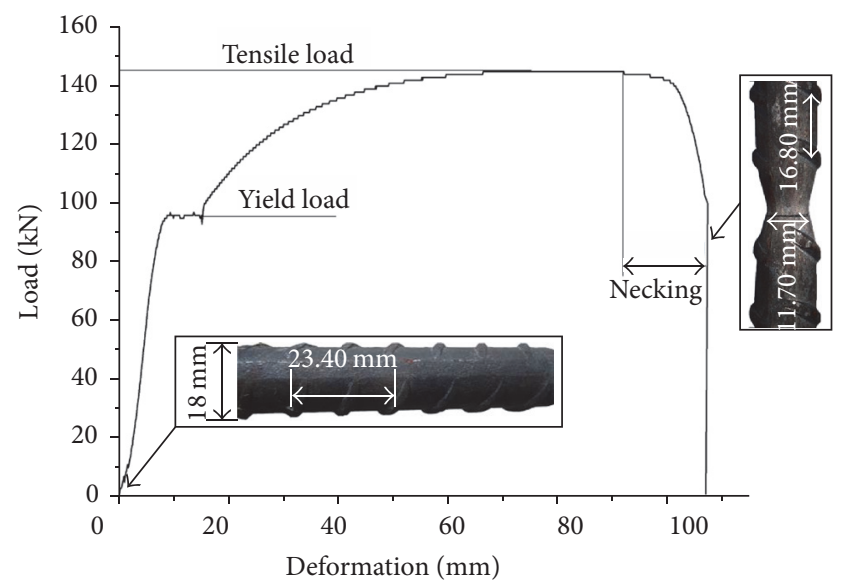

Figure 6: Deformation-load behavior of a standard bolt under tensile test.

pullout tests; thus a standard tensile test was carried out firstly. The deformation-load relationship can be plotted out by recording changing amount of tensile load at different intervals of deformation; the result is shown in Figure 6. The initial diameter and rib spacing of the bolt were $18 \mathrm{~mm}$ and $11.70 \mathrm{~mm}$, respectively. The bolt was elongated elastically until the deformation reached $8.5 \mathrm{~mm}$, which was then followed by a yield load at $96 \mathrm{kN}$ or so lasting for a deformation of $6.1 \mathrm{~mm}$. Afterwards, the curve showed a convex trend until a tensile load of $145 \mathrm{kN}$ was reached, where the deformation was $66.50 \mathrm{~mm}$. The bolt continued to elongate at the level of the tensile load until the initiation of necking at a displacement of approximately $95.02 \mathrm{~mm}$. Finally, the bolt failed at a deformation of $107.43 \mathrm{~mm}$, accompanied by a brittle failure. Bolt diameter at the failure point was $11.70 \mathrm{~mm}$, and the rib spacing neighboring the failure point was extended to $16.80 \mathrm{~mm}$. 


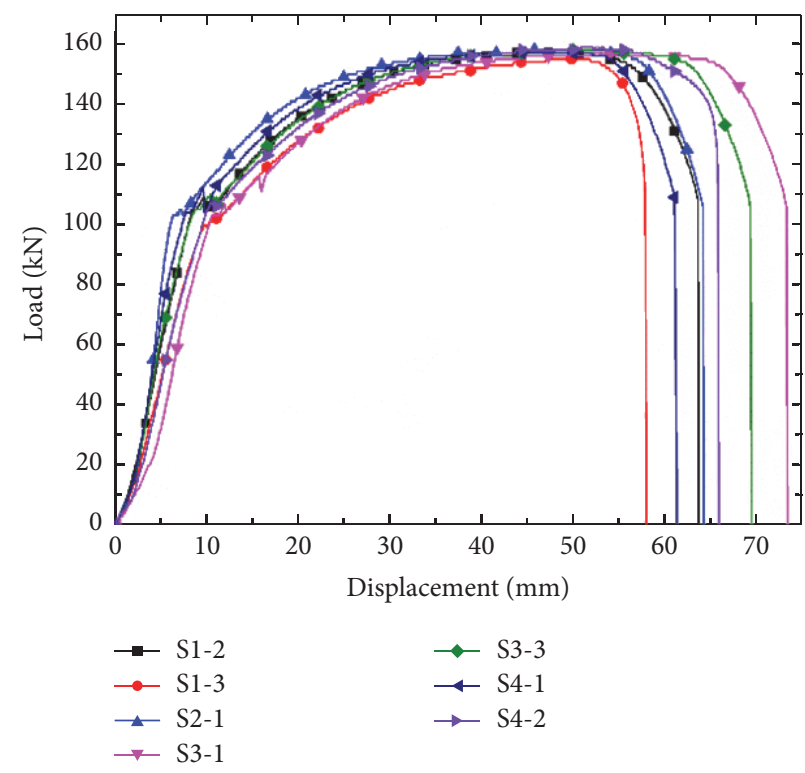

(a)

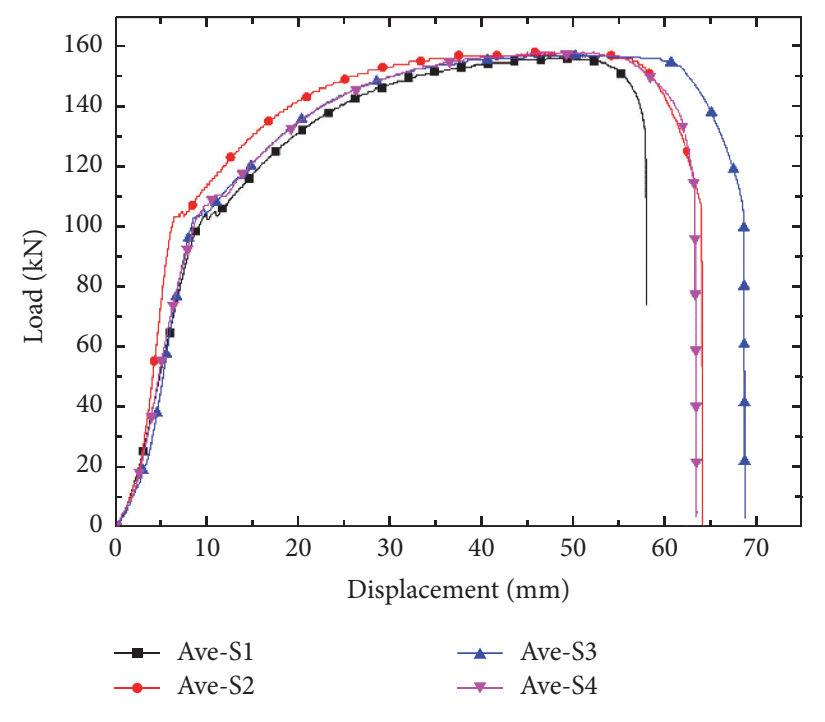

(b)

FIGURE 7: Load-displacement relationship (a) and average curves (b) for samples terminated by bolt fracture during pullout tests.

5.2. Testing Results for Samples Damaged by Bolt Fracture. The termination of the pullout tests is mainly caused by decoupling at bolt-grout interface if bolt tensile strength is large enough; the decoupling progressively extends in a way from bolt-clamp end to tube-clamp end in theory, and the interface successively undergoes three kinds of contacting states, namely, the elastic, softening, and decoupling state [19]. However, several pullout tests were prematurely interrupted due to the unpredictable tensile fracture of the bolt. This was mainly caused by the dramatic contrast on ultimate strength between cement and bolt, and the bolt tensile strength was not large enough to transfer the pullout load to cement and further isolate the bonding state between bolt and cement. Their load-displacement curves were gathered together in Figure 7(a). By overall analysis, a common point could be observed, which showed the length for the last segment of all fractured samples was $15 \mathrm{~cm}$. The $15 \mathrm{~cm}$ segment of steel tube was the longest one among all segments, as can be interpreted from Table 1. Consider static equilibrium relationship of a bolt suffering tensile test; the exposed bolt end undertook identical load as what the tubeclamp end did; then the last segment suffered the largest pullout load among all segments; this theory has already been illustrated in Figure 3. Afterwards, the adhesive face between the last segment and the last but one segment would be prior detached under the ascending pullout force sourcing from MTS machine. This process was accompanied by decoupling at bolt-grout interface, and the decoupling would extend to both sides of the separation [22, 23]. Afterwards, two forms of final fracture should exist; the first one was complete interface decoupling, which might occur if the bolt could be finally pulled out from the tube; the second one was bolt fracture during pullout procedure, which occurred if the bolt elongation rate surpassed relative displacement between bolt

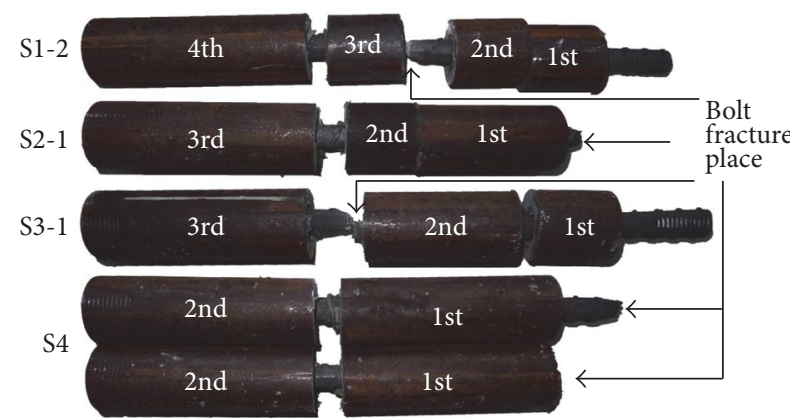

FIGURE 8: Fracture forms for fractured samples S1-2, S2-1, S3-1, and group S4.

and grout. Failure for current case belonged to the second one; if the bolt elongation between the detached segments took advantage, then the fracture place was as what samples 12 and 3-1 have shown in Figure 8; if the bolt elongation closing bolt-clamp end took advantage, then the fracture place was as what sample 2-1 and groups 4 have shown in Figure 8.

Plus, these curves showed high degree of similarities with each other; they almost shared the identical elastic trend and plastic trend; their peak strength also showed little difference at $158 \mathrm{kN}$ or so, with corresponding displacement approximately positioned at $48 \mathrm{~mm}$. The pullout load firstly came through an approximate linear increase to $105 \mathrm{kN}$ with respect to a displacement ranging from $7 \mathrm{~mm}$ to $11 \mathrm{~mm}$, depending on their different combining forms. Then they all experienced a similar yield process under relatively small elongations no more than $4 \mathrm{~mm}$. Afterwards, they all showed a convex trend to their peak load and enduring certain deformation until a sudden brittle bolt fracture occurred. In 
TABLE 2: Characteristic parameters for tensile test on bolt and pullout test interrupted by bolt-fracture.

\begin{tabular}{|c|c|c|c|c|c|c|}
\hline Testing measure & $\begin{array}{l}\text { Yield load } \\
\qquad(\mathrm{kN})\end{array}$ & $\begin{array}{l}\text { Elastic elongation } \\
\qquad(\mathrm{mm})\end{array}$ & $\begin{array}{l}\text { Yield lasting } \\
\quad(\mathrm{mm})\end{array}$ & $\begin{array}{l}\text { Peak load } \\
\quad(\mathrm{kN})\end{array}$ & $\begin{array}{c}\text { Displacement } \\
\text { versus peak } \\
\text { load (mm) }\end{array}$ & $\begin{array}{c}\text { Final } \\
\text { displacement } \\
(\mathrm{mm})\end{array}$ \\
\hline Tensile test & 96 & 8.5 & 6.1 & 145 & 66.50 & 107.43 \\
\hline Pullout test & 105 & $7 \sim 11$ & $\leq 4$ & 158 & 48 & $55 \sim 75$ \\
\hline
\end{tabular}

order to more clearly investigate the differences among them, here Figure 7 (b) presents the respective average curves for these four groups of pullout test; it can be seen that group S3 had the largest displacement whereas group S1 had the smallest one. And S2 had the largest load to displacement ratio based on changing trend in linear increasing section, the lagging detachment between the last segment and the last but one segment contributed to a relatively longer sustainability of the whole intact interface; it thus intensified the rigidity of the bolting system.

Though in some ways all curves may look similar with the bolt tensile test plotted in Figure 6, their characteristic points do show strengthened effects. The common point was that their fracture belonged to tensile fracture of bolt; hence it should be meaningful if their characteristic parameters were compared; see Table 2. It can be seen that the mechanical properties of grouted bolt were some kind of intensified; the yield load and peak load for pullout test were magnified whereas corresponding displacements were sharply decreased. It is a remarkable fact that the elastic elongation for different measures showed no big difference, which indicates that the early stage for pullout test was also determined by bolt elongating property. The yield lasting displacement for pullout test decreased to a value less than 4 , which was due to the fact that most length of bolt was annularly bonded by cement and its yield performance was restrained to some extent.

5.3. Testing Results for Groups S1-S3 Damaged by Interfacial Decoupling. As stated in former sections, the failure forms for a bolting system under pullout test can be divided into two types; they are bolt fracture and interfacial decoupling; now interfacial decoupling is studied in this section. The length of the last segment for groups S1 S3 was $15 \mathrm{~cm}$, and their pullout results showed certain similarities, but the samples failed by bolt fracture were excluded; they were S1-2, S1-3, S2-1, S3-1, and S3-3. S1-1 and S2-2 were also excluded due to the large section of voids between bolt rod and steel tube; the tests on them were terminated at a relatively low pullout load. The voids were caused by directly pouring cement during samples preparation procedure, but the injector adopted later solved the problems. Hence, only samples S2-3 $(15+5+10)$ and S3$2(15+10+5)$ were left for analysis in this section, which we hope can reveal failure mechanism of bolting system under this kind of segments combining form; the load-displacement relationship for these two samples is plotted in Figure 9.

From the curves plotted in Figure 9, it seems that the early linear section, mainly determined by displacement-load mechanism of bolt, was well adapted to the equivalent linear section of the curve shown in Figure 6. But the overall curve trend in Figure 9 was multiply determined by mechanical properties of bolt, cement, and bolt-grout (or grout-tube) bonding effects, which sustained an overall stability of bolting system before failure occurred. For sample S2-3, the peak load was $156 \mathrm{kN}$ with respect to a displacement of $48 \mathrm{~mm}$; then the load directly dropped from its peak load to $90 \mathrm{kN}$ experiencing a displacement of $6 \mathrm{~mm}$; sample S3-2 shared a similar decreasing process as the former did. After the first significant drop of load value, both of the samples endured another round of load increase, and this kind of similar load oscillation repeated three or four times for both samples. Another observation was that the amplitude of the oscillation showed a general increase trend; take S3-2 for example; the peak loads from the first cycle to the third cycle were $132 \mathrm{kN}$, $144 \mathrm{kN}$, and $146 \mathrm{kN}$, respectively. After the oscillations, the load rapidly decreased to an approximate zero level; the final displacements for S2-3 and S3-2 were $129 \mathrm{~mm}$ and $161 \mathrm{~mm}$, respectively. Figures 9(b) and 9(c) present the top-views of the last segments (15 cm in length) of S2-3 and S3-2; it can be seen that part of the cement close to the bonding end was highly disintegrated; the largest breakage depths for S2-3 and S3-2 are $34.95 \mathrm{~mm}$ and $39.98 \mathrm{~mm}$, respectively. Cement breakage for the rest section was invisible to the naked eye, but it was for sure that incubation of unobservable cracks should exist.

In actual mining sites, it is normal to observe load oscillation of an installed bolt; the incentives can come from various aspects, such as nearby mechanized excavation, blasting, and strata stress variation. Figure 10 shows the crests and troughs for oscillation section along the curves shown in Figure 9(a); it seems that the changing law for troughs fitted well a linear increasing trend whereas the changing law for crests showed a quadratic parabola relationship. Overall, the gradual approach trend for crests and troughs indicated the decreasing trend of oscillation amplitude. But it deserves attention that the amplitude for S2-3 was relatively smaller than S3-2, which is reasonable if we take the length of middle segments of S2-3 $(5 \mathrm{~cm})$ and S3-2 $(10 \mathrm{~cm})$ into consideration. After the occurrence of ends detachment between the last segment and the middle segment, the degree of decoupling bilateral the separation and the bolt elongation were vital to overall stability of bolting system. A $5 \mathrm{~cm}$ long middle segment in S2-3 was easier to be fully decoupled or be detached with the first segment, causing energy consumption on segments detachment and bolt elongation between the first segment and the middle segment. Then its first drop from peak load was brought forward to compensate the energy consumption; the oscillation amplitude and breakage depth were also comparatively smaller than those of S3-2, 


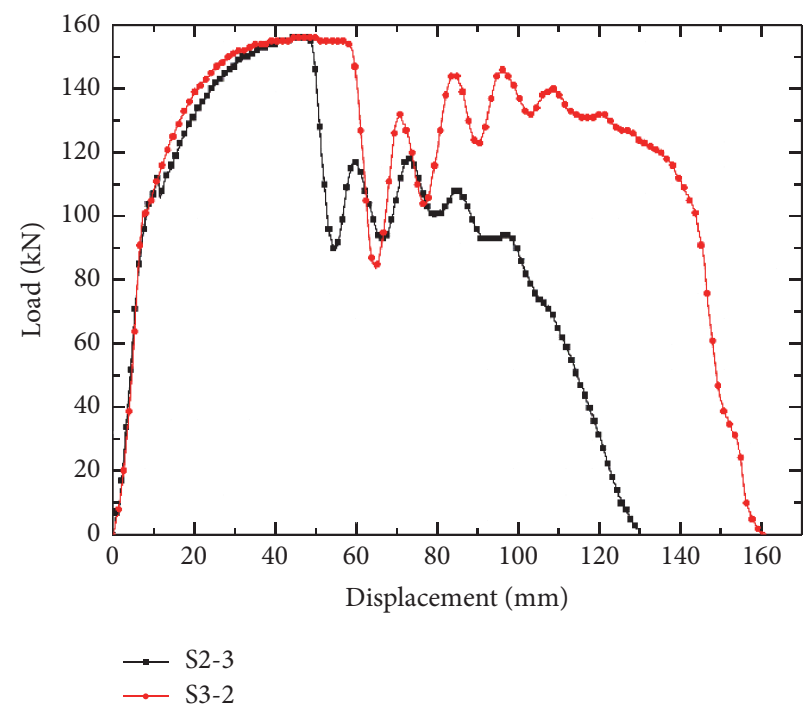

(a)

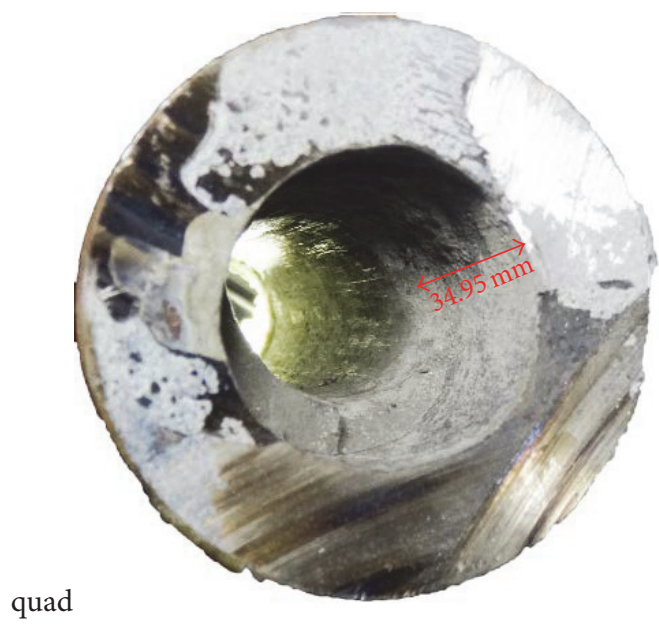

(b)

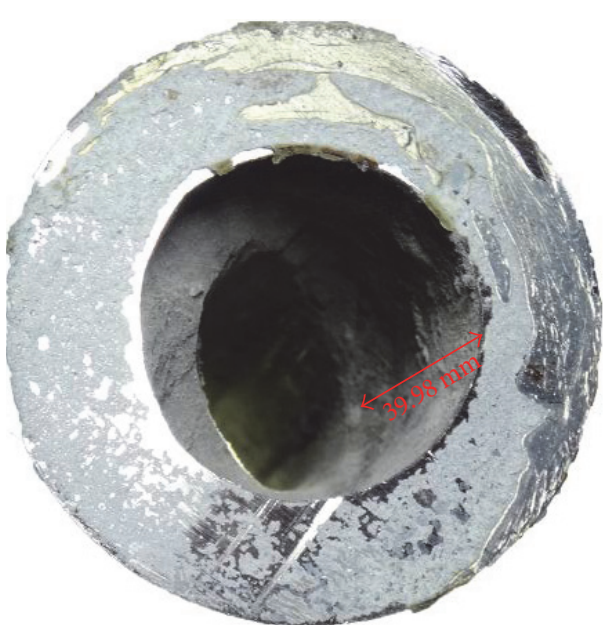

(c)

FIGURE 9: Load-displacement relationship (a) for samples S2-3 $(15+5+10)$ and S3-2 $(15+10+5)$ terminated by interfacial decoupling and respective end views ((b), (c)) for them.

as indicated by comparing subfigures in Figure 9; similar phenomenon will be further probed in Figure 14. Inspired by the results, it can be concluded that a relatively thicker layer of rock mass is positive to bolt supporting in underground engineering.

5.4. Testing Results for Samples S5. The combination form for samples S5 was $9+7+7+7$; that is, the first segment was $7 \mathrm{~cm}$ and the last one was $9 \mathrm{~cm}$. Test results for this group of samples showed some specialties, as plotted in Figure 11(a). Overall, the peak load was reached with respect to a relatively smaller displacement as compared with aforementioned examples; all of the peak load was lower than $140 \mathrm{kN}$. However, their elastic stage, determined by bolt's elastic property, kept similar trend by a displacement range at $10 \mathrm{~mm}$ or so.

In view of curves trend, it seems that the failure form for samples S5-1 and S5-3 was caused by sudden bolt fracture as cases analyzed in Section 5.2, but their actual situation was absolutely different. For sample S5-1, the load reached its peak value $131 \mathrm{kN}$ at an axial displacement of $23 \mathrm{~mm}$, when the interfacial decoupling had already fully developed at the last segment $(9 \mathrm{~cm})$. The rest bonding section between bolt and cement in this segment was not able to sustain the overall stability of bolting system under the circumstance; hence the load rapidly dropped to zero level after the peak load point [22]. We manually pulled out the last segment and measured the fracture length of the cement annulus after the test; the fractured length was $56.95 \mathrm{~mm}$, accounting $63.28 \%$ of the total length of the last segment; see Figure 11(b). Hence, the rest contact area was not able to sustain a relatively high load of $131 \mathrm{kN}$; then the load rapidly dropped to zero under the effects of sliding friction at bolt-cement interface with a final displacement of $44 \mathrm{~mm}$. S5-3 had undergone a different evolution mechanism; the load abruptly decreased to zero from the peak value $140 \mathrm{kN}$ with respect to the 


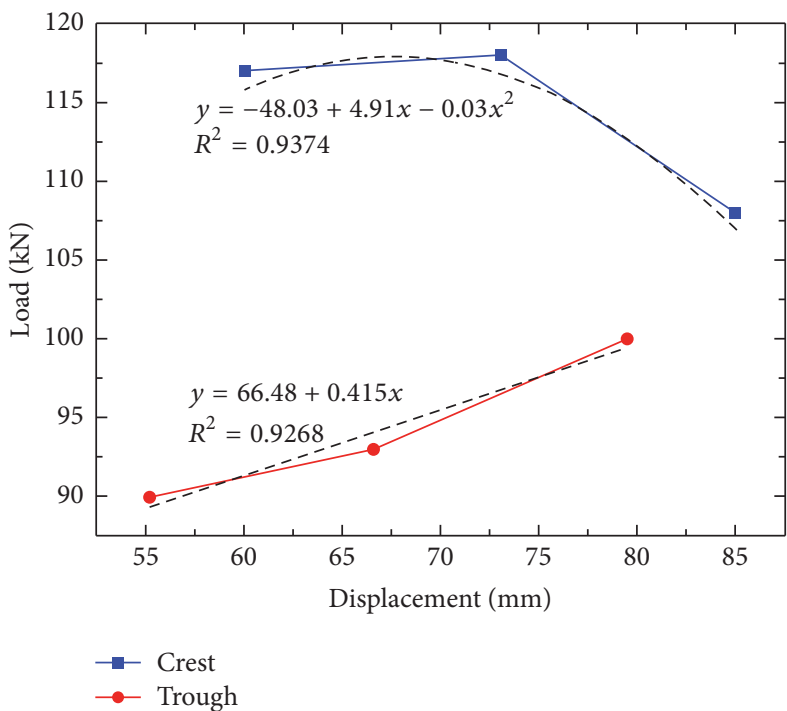

(a)

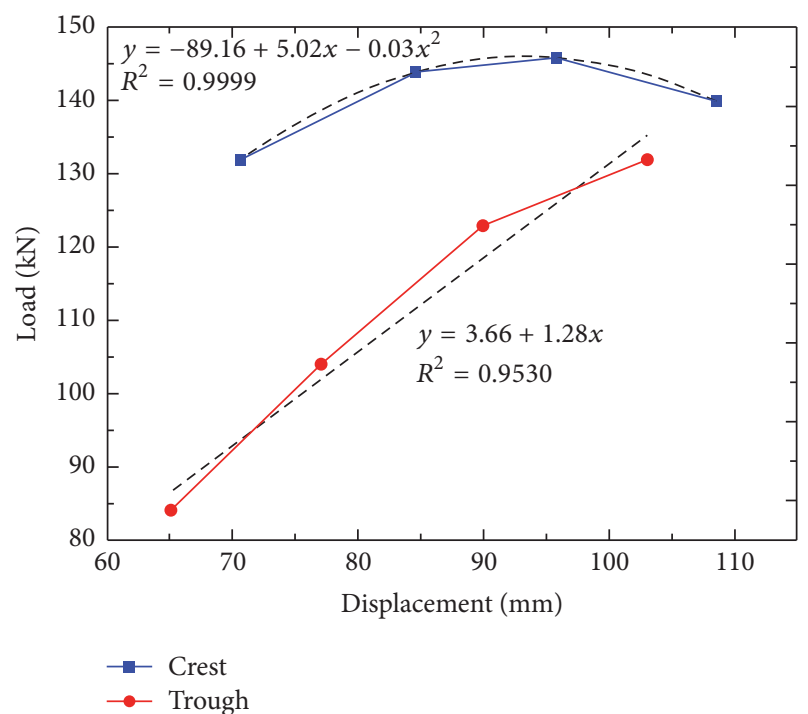

(b)

FIGURE 10: Crests and troughs fitting for oscillation of samples S2-3 (a) and S3-2 (b).

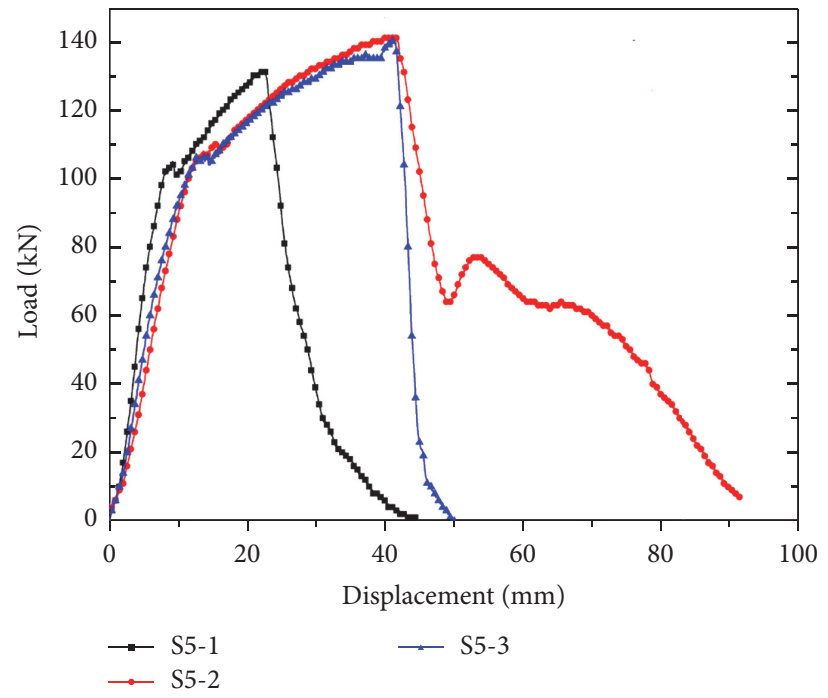

(a)

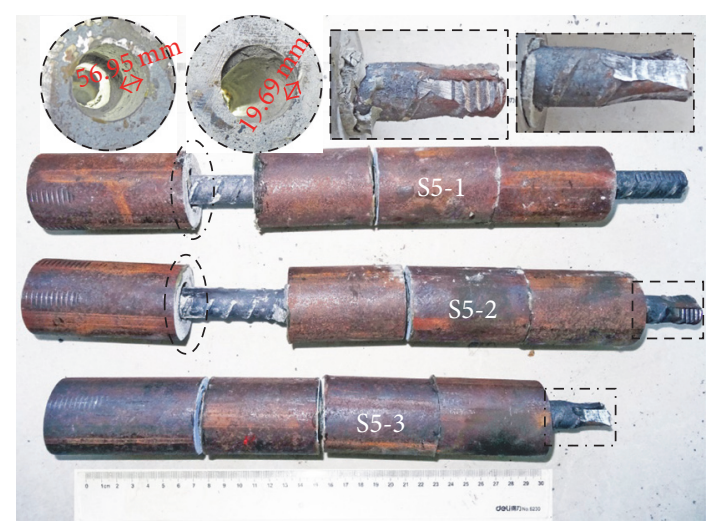

(b)

FIGURE 11: Load-displacement relationship for samples S5 (a) and their failure photos (b).

displacement of $42 \mathrm{~mm}$. However, its actual sharp decrease of load was actually caused by severe deformation of bolt end due to overlarge clamping force of the test machine (see dot-and-dash rectangle in Figure 11(b)), which incurred the unexpected detachment of the bolt from the clamp during pullout test; otherwise the curve should have evolved further.

Unlike what S5-1 and S5-3 experienced, S5-2 presented a complete process of load-displacement relationship; the progressive interfacial decoupling was monitored during test. Different with samples S2-3 and S3-2, the cycle number for load oscillations only occurred once; relevant amplitude for the oscillation, ranging from $64 \mathrm{kN}$ to $76 \mathrm{kN}$, was also comparatively smaller than S2-3 and S3-2. Afterwards, it gradually decreased to the approximate zero level with respect to a final displacement of $92 \mathrm{~mm}$. By disclosing the inner view of the last segment, see dotted circle in Figure 11(b), the maximum value for cement fracture depth was $19.69 \mathrm{~mm}$, whereas the rest section kept a visualized intact state; it thus confirms the evolution model for bolting failure procedure presented in Figure 3. Even the last segment of S52 had a longer residual intact length as compared with S51; the stress state was identical when load dropped to zero, namely, decoupling state or fraction state. Aforementioned analysis indicates that a $9 \mathrm{~cm}$ long steel tube positioned at the last place cannot provide stable and long-term support effects. 


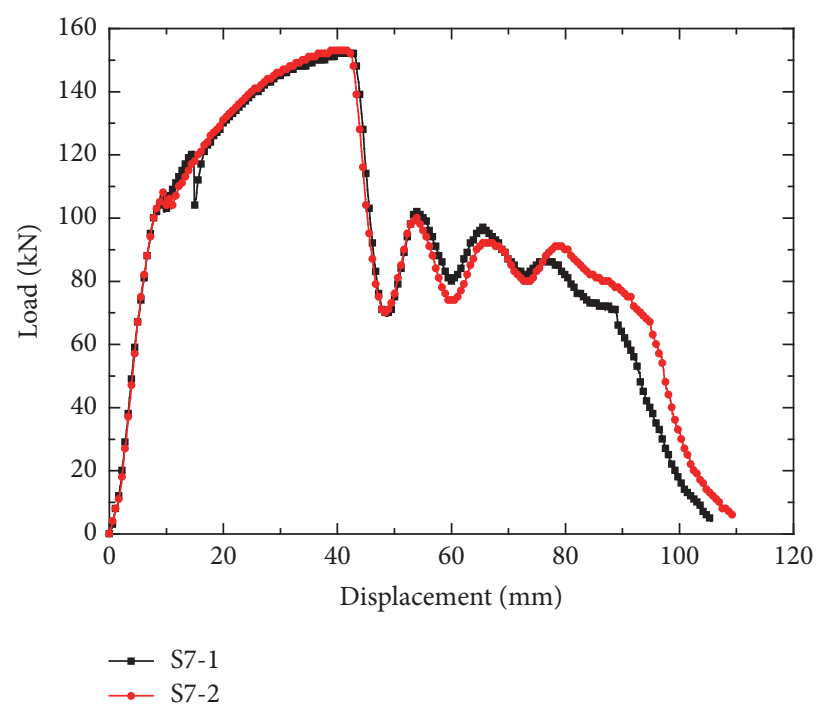

(a)

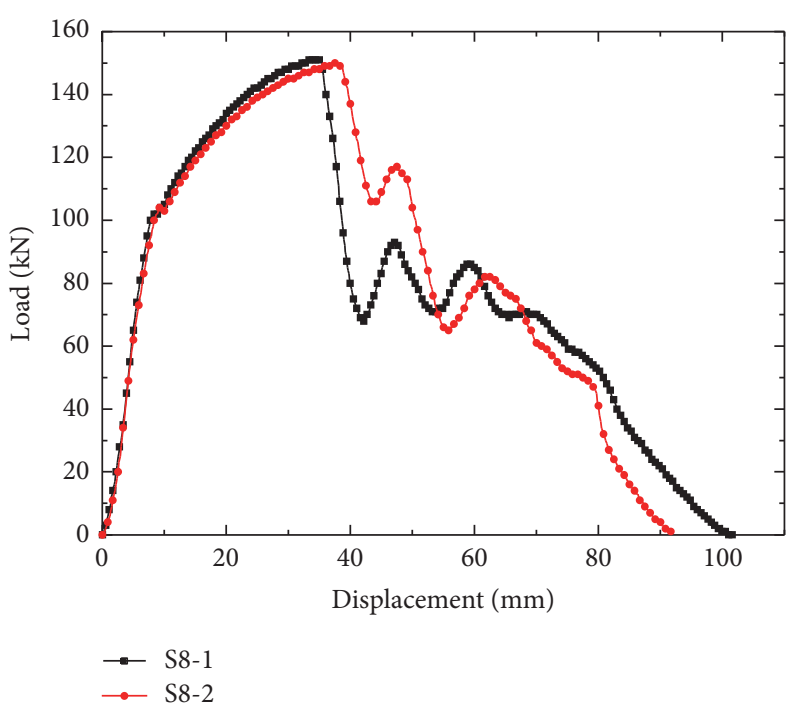

(b)

FIGURE 12: Load-displacement relationship for samples S7 and S8.

At last, the second segment and the third segment also detached with each other during test, as indicated in Figure 11, which lagged the detachment between the third one and the last one; it demonstrates that both of the $5 \mathrm{~cm}$ long segment and $7 \mathrm{~cm}$ long segment neighboring the last one are easily isolated under ascending pullout force.

5.5. Testing Results for Samples S6, S7, and S8. The length for the last segment of samples S6 $(10+5+15)$, S7 $(10+10+10)$, and S8 $(10+15+5)$ was $10 \mathrm{~cm}$ long; their load-displacement relationships are presented in Figure 12. As can be interpreted from Figure 12(a), load-displacement relationship for samples S7-1 and S7-2 almost kept an associated pattern. The linear increase of load before $10 \mathrm{~mm}$ was primarily determined by bolt elastic response; consequent small shock on the curves indicated the transition from linear reaction to plastic reaction of bolt; then the curves were followed by a duration of convex process till the arrival of the peak load, $153 \mathrm{kN}$ accompanied by a displacement of $43 \mathrm{~mm}$. Then the first cycle of sudden decrease started from peak load to $69 \mathrm{kN}$ with respect to a displacement variation of $8.6 \mathrm{~mm}$; afterwards, three cycles of load oscillations could be apparently observed; the oscillation law will be explicitly stated and compared as what occurred in S8-1 and S8-2 in following parts. At last, both of the curves headed to the zero-load level and finally finished the whole procedure with final displacements of $106 \mathrm{~mm}$ and $110 \mathrm{~mm}$, respectively.

Early-stage load-displacement evolution for group S8 was identical to group S7 (see Figure 12(b)), but the differences showed out after the arrival of peak load. For one thing, the oscillation pace for group S8 was not that coordinate as what group S7 experienced; for another, changing pace for S8-2 lagged behind that of S8-1 when the displacement varied between $9 \mathrm{~mm}$ and $68 \mathrm{~mm}$. A possible explanation for the lagging appearance should be the relatively later occurrence of first detachment of tubes for sample 8-2, and the detachment acted as premature weakening effects to overall stability of bolting system.

The length for the last segment of groups S6, S7, and S8 was unified $10 \mathrm{~cm}$; hence it should be instructive to comprehensively analyze their commons and differences. As shown in Figure 13, the average curves for groups S7 and S8 were fitted and testing curve for $\mathrm{S} 6$ was also added. The figure indicated that group S6 shared a high coordination with AveS7 before the end point of the last oscillation. However, the arrival of peak load, decreasing amplitude, and oscillation times for Ave-S8 showed a premature trend. Furthermore, fracture forms presented in Figure 13(b) can serve as an auxiliary interpretation; note that the separated segments (leftward $10 \mathrm{~cm}$ long ones for S6 and S7) were automatically detached during pullout test, but the rightward tube-bonded sections still kept tight and the tubes could not be manually taken off from the assembly due to the residual fractional resistance along the interface.

The reason for cooperative changing pace between S6 and Ave-S7 can be interpreted from energy transformation perspective. It has been acknowledged by scholars that bolt pullout test is accompanied by energy-absorbing process [24], where the input source is MTS machine, and the output path contains heat generating of bolt, fracture of cement, fraction along bonding interfaces, acoustic energy, and so forth. Generally, the overall energy of a bolting system under pullout test can be described by the area covered by load-displacement curve. On account of aforementioned explanation, it can be understood that if the rest combining segments gradually detached with each other after the first detachment between the last segment and the middle one, then the detachment between segments gave space to consume more energy, especially for bolt elongation. Figure 13(b) indicates that the first segment and the second segment subsequently detached with each other under the ascending pullout load; thus energy was further consumed on bolt 


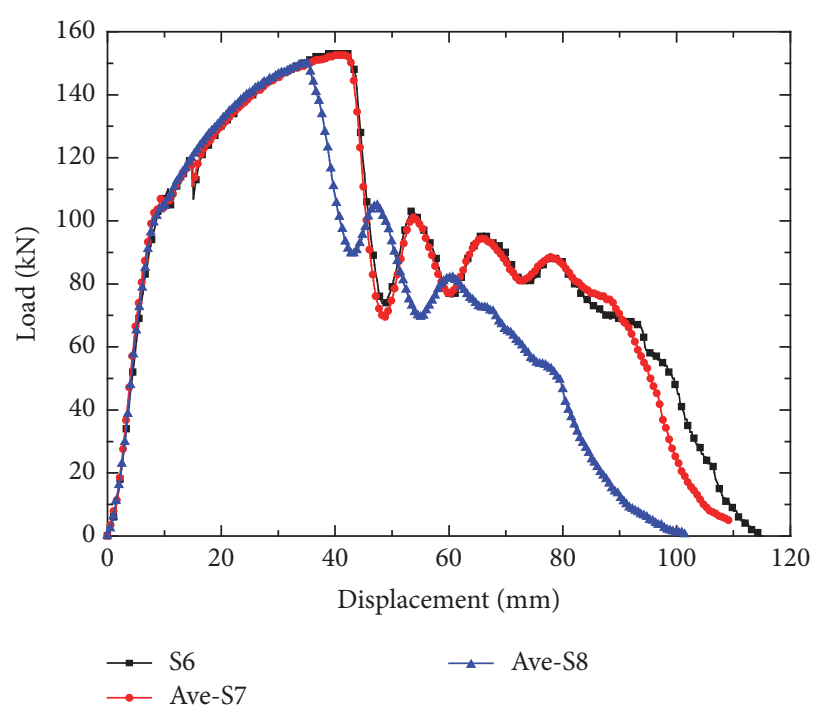

(a)

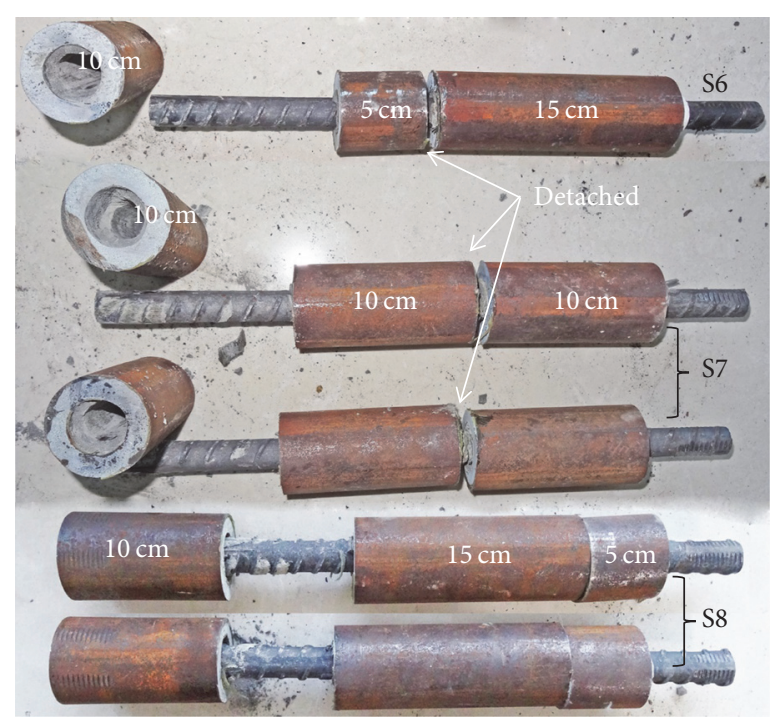

(b)

FIGURE 13: Load-displacement relationship comparison among S6, S7, and S8 (a) and relevant fracture forms (b).

elongation and cement breakage around the separation; then the area under load-displacement curves for S6 and Ave-S7 is larger than Ave-S8. On the contrary, if the rest bonded segments kept original intact and integral state after the first detachment between the last segment and the middle one, then the energy consumption was largely concentrated at the bonding interface of the last segment $(10 \mathrm{~cm})$, which induced stress concentration and rapid bonding state alteration along the interface; see example S8. This process played as an adverse effect to overall stability of the bolting system; then a premature failure of the system accompanied by lower peak load, lower oscillation duration, and smaller displacement was apparent.

From another perspective, it can be seen that if the length for the segment neighboring the last one was $10 \mathrm{~cm}$ or less, such as $5 \mathrm{~cm}$ and $7 \mathrm{~cm}$, then its adhesion with the first (threesegment combination patterns such as groups S2, S3, S6, and S7) or the second (four-segment combination patterns such as groups S1, S5) segment would be easily isolated. However, the situation would alter to reverse side if the segment neighboring the last one was $15 \mathrm{~cm}$; its right end detachment was hard to occur (group S8). Theoretically, the elongation of the exposed bolt rod contributed a relatively larger amount of displacement as compared with the rest section; this was mainly because of the fact that the elongation along the rest bolt rod was still some kind of "protected" by steel tube; the cement annulus in the tube coated the loaded bolt to resist bolt elongation. The disequilibrium displacement would evolve in the first and the second segments; the $15 \mathrm{~cm}$ long segment had a larger contact area with the inner bolt to sustain the deformation. It thus acted as protection effects to its right-hand neighboring $5 \mathrm{~cm}$ long segment; then the contacting ends between the first and the second segments of S8 kept intact during the whole test whereas corresponding segments of S6 and S7 were detached during the test, as shown in Figure 13(b). Aforementioned theory is vividly drawn in Figure 14; it thus demonstrates that the strata with relatively larger thickness are positive to the stability of bolting system.

In order to analyze the oscillation mechanism in Figure 13(a), the crest and trough for each cycle of load oscillation versus displacement are studied (see Figure 15). It may be concluded from Figures 15(a) and 15(b) that the crests for S6 and S7 expressed a descending trend, and this trend met a linear expression very well; both of the correlation coefficients reached up to 0.99 . Changing pattern for troughs, however, showed an ascending trend; the fitted equations revealed an approximate linear increasing relationship. The variation trends of crests and troughs gradually approached to each other as the oscillation continued, which indicates that the amplitude for oscillation was turning smaller. Load cycle for Ave-S8 only recycled twice, and Figure 15(c) demonstrates that the connecting lines almost parallel with each other; this is because of the fact that decoupling length and load bearing capacity loss in the second oscillation were almost identical to the corresponding amounts in the first one.

5.6. Integral Comparison and Analysis. Based on all of these tests, their characteristic parameters are gathered together in this section; see Table 3. By extracting data and comparative analysis, following laws can be obtained from Table 3 :

(1) For a failure caused by interfacial decoupling, the final displacement is closely related to the length of the last segment. The longer the last segment is, the larger the final displacement will be. Among them, the largest final displacement is $161 \mathrm{~mm}$, which is almost four times larger than the smallest one, only $44 \mathrm{~mm}$, reached by $55-1$.

(2) Value for peak load and value for displacement corresponding to peak load have a high correlation with the length of the last segment; longer length 

This segment is vital
to sustainability

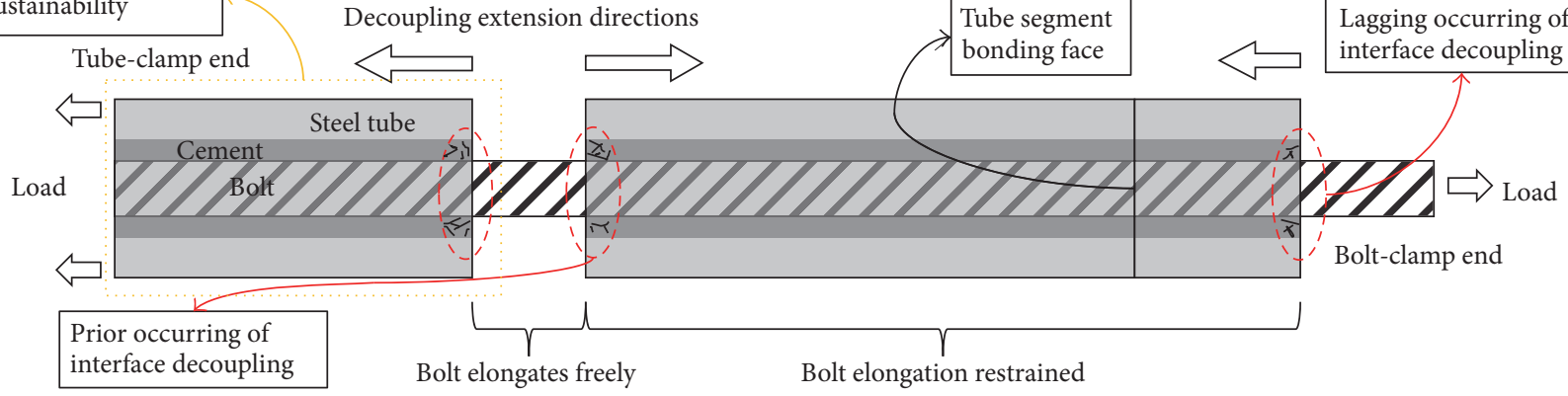

FIGURE 14: Disequilibrium relation between bolt elongation and interfacial decoupling.
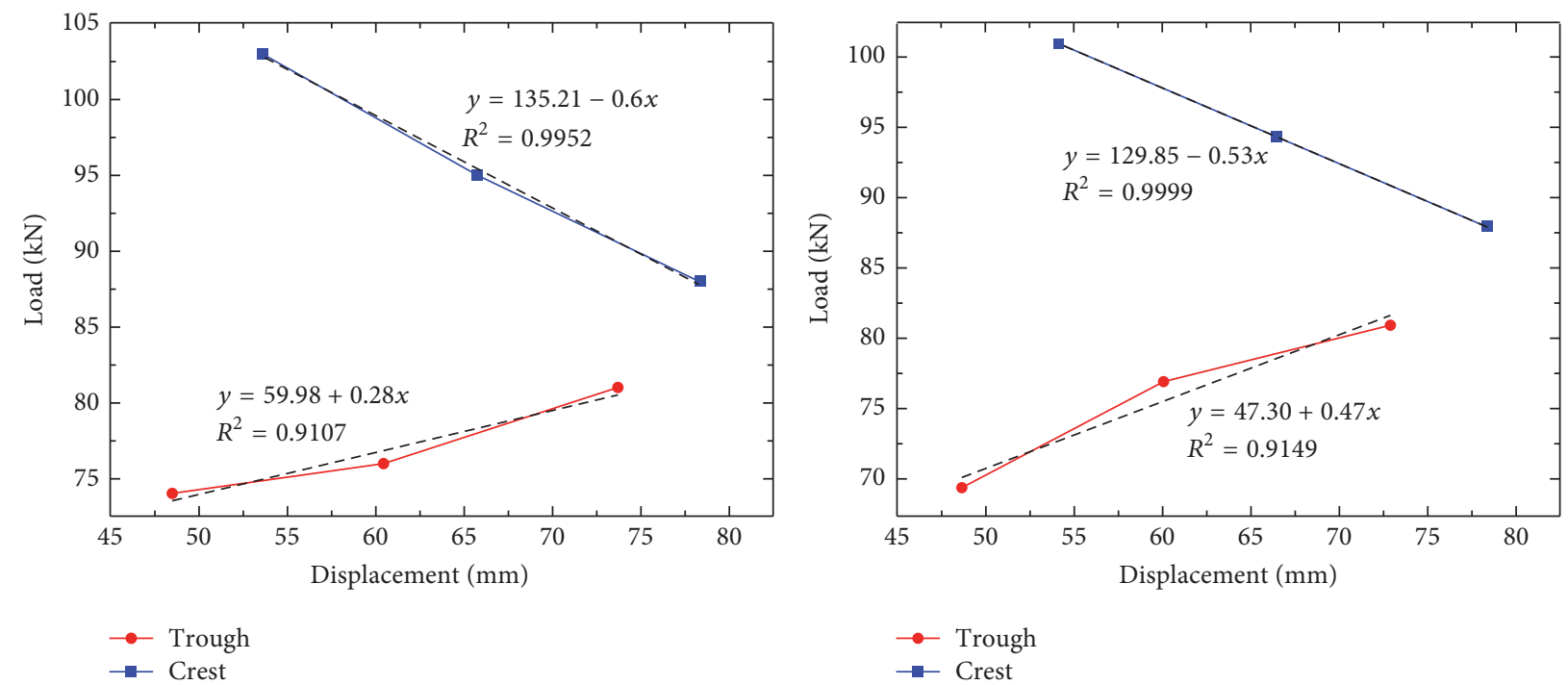

(a)

(b)

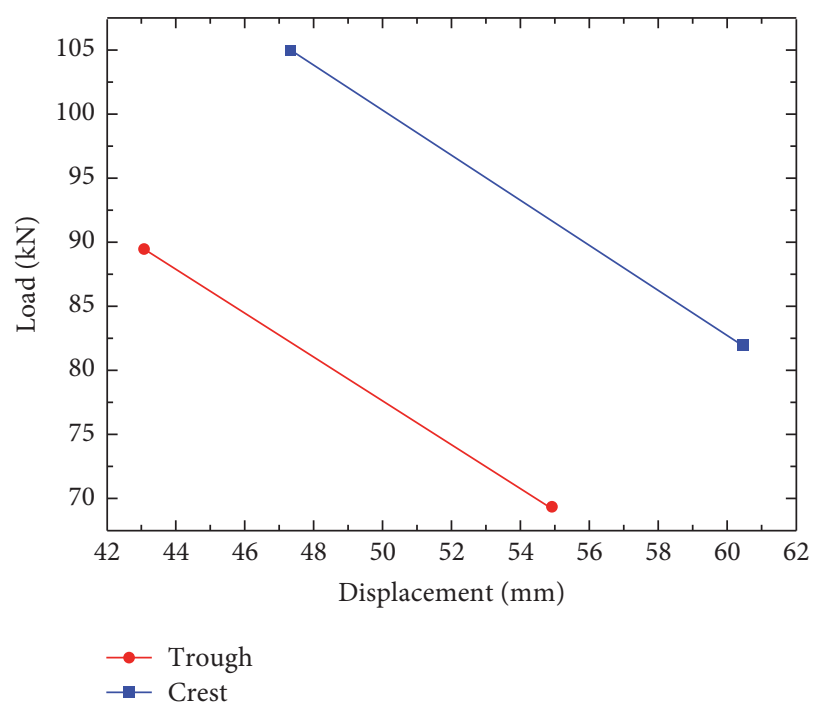

(c)

FIGURE 15: Crests and troughs for load oscillation of samples S6 (a), S7 (b), and S8 (c). 


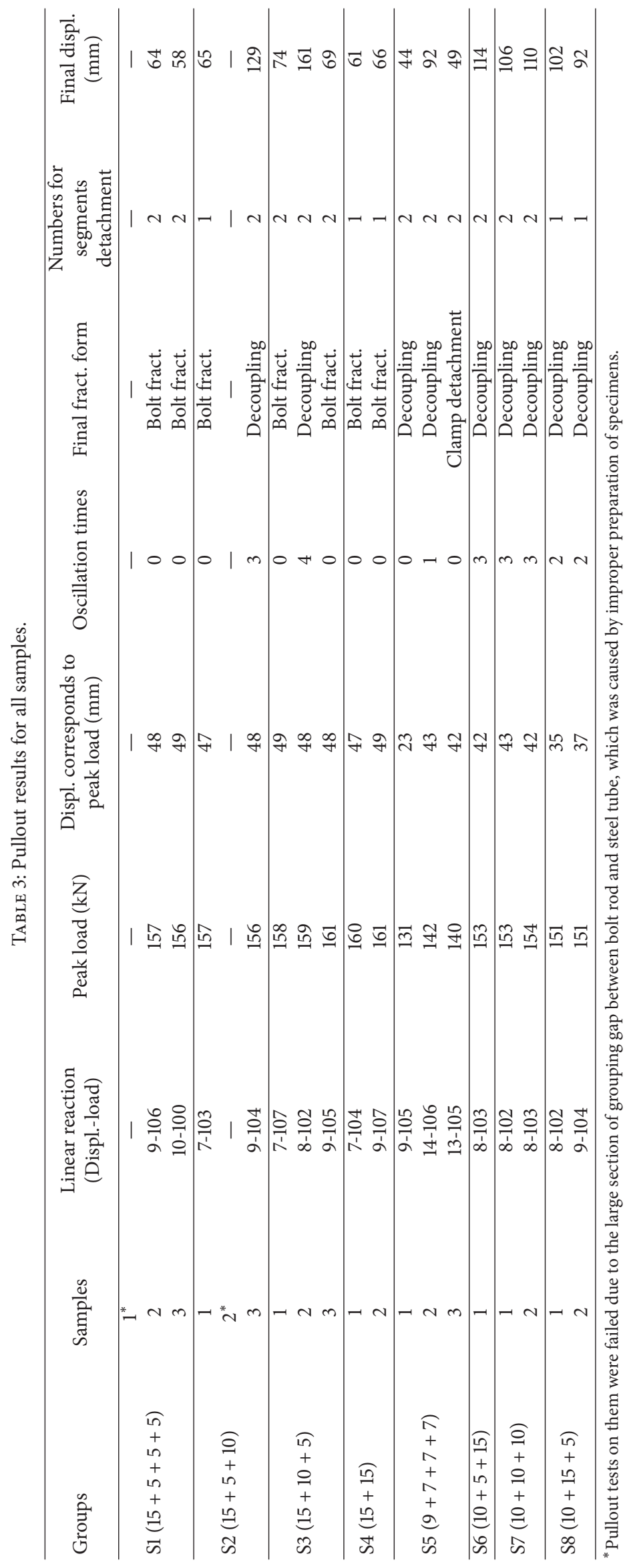


of the last segment will lead to the higher values for peak load and corresponding displacement. Take S5-1 for example; its peak load and corresponding displacement are $131 \mathrm{kN}$ and $23 \mathrm{~mm}$, respectively, whereas the equivalent values for S3-1 are $158 \mathrm{kN}$ and $49 \mathrm{~mm}$, respectively.

(3) Failure caused by bolt tensile fracture is more likely to occur if the length of the last segment is larger than $15 \mathrm{~cm}$; otherwise the failure caused by interfacial decoupling is more likely to occur. Regardless of the difference, the early stage of the linear relationship in L-D curves shows no obvious differences among different groups of samples, which is mainly determined by linear mechanical properties of the utilized bolt under tensile test.

(4) The segments detachment times during pullout test are some kind of related with the length of the last segment but one in the combined tubes; if this segment has a length of $15 \mathrm{~cm}$ or so, then the bolt elongation in this segment is restrained to some extent, accompanied by relatively fewer detachment times.

\section{Conclusion Remarks}

(1) Laboratorial pullout test on bolting system generally adopts steel tube to simulate rock mass to evaluate mechanical capacity of a specific bolting measure. The stress distribution of steel tube shows a reverse pattern with the stress distribution of the bolt under pullout test; the stress exponentially drops from tube-clamp end to bolt-clamp end. Under the combination of varied length of steel tubes, the detachment of two neighboring tubes will firstly occur between the last two segments; then the rest detachments will extend to bolt-clamp end. However, this kind of extension will be interrupted if an approximate $15 \mathrm{~cm}$ long segment is met; it provides resistance effects to the relevant elongation of its inner bonded bolt, and thus its neighboring ends along extending direction are protected from being detached.

(2) Bolt tensile fracture is the main factor that leads to bolting system failure if the length of the last segment is $15 \mathrm{~cm}$ or more; though it shares identical fracture form with individual bolt tensile test, the mechanical properties of the former are intensified to some extent. If the last segment is $10 \mathrm{~cm}$ or less, then the failure caused by interfacial decoupling is surely to occur. No matter in what kind of failure forms, the early stage along all of their load-displacement curves is completely characterized by a linear increasing stage, which is mainly determined by linear mechanical properties of the utilized bolt under tensile test.

(3) In most circumstances, load oscillation occurs if the fracture form belongs to interfacial decoupling; the oscillation is induced by progressive decoupling at bolt-grout interface. The crest evolution shows a quadratic parabola relationship whereas the trough shows a linear increasing trend for samples with the last segment defined as $15 \mathrm{~cm}$ long; if this segment is $10 \mathrm{~cm}$ long, then the crest evolution shows a linear decreasing trend whereas the trough evolution shows a linear increasing trend.

(4) If the length for last segment is defined as $9 \mathrm{~cm}$ or less, then this segment will be too short to counterbalance the steady growth of pullout load. It is believed that the segments detachment will occur in no time once the test begins, and the progressive decoupling at the bolt-grout interface in the last segment will also prematurely show out, which directly leads to the bearing load deficiency during the load-ascending procedure.

(5) If the bolting system is terminated by interfacial decoupling, then the final displacement in pullout test is highly associated with the length of the last segment; the relationship shows a positive correlation. This correlation is also applicable to the peak load and its corresponding displacement; their values also increase as the length for the last segment rises.

\section{Competing Interests}

The authors declare that they have no competing interests.

\section{Acknowledgments}

The authors would like to acknowledge the financial support for this study from the Program (IRT_14R55) for Innovative Research Team in University by Ministry of Education of China, Project 51274193 supported by National Natural Science Foundation of China, Science and Technology Project of Ministry of Education of China (113030A), and Priority Academic Program Development of Jiangsu Higher Education Institutions. The comments and suggestions from Wanxing Song in State Key Laboratory of Coal Resources and Safe Mining (CUMT) are highly appreciated.

\section{References}

[1] G. S. Esterhuizen and I. B. Tulu, "Analysis of alternatives for using cable bolts as primary support at two low-seam coal mines," International Journal of Mining Science and Technology, vol. 26, no. 1, pp. 23-30, 2016.

[2] J. Chen, P. C. Hagan, and S. Saydam, "Parametric study on the axial performance of a fully grouted cable bolt with a new pullout test," International Journal of Mining Science and Technology, vol. 26, no. 1, pp. 53-58, 2016.

[3] S. S. Peng, "Topical areas of research needs in ground controla state of the art review on coal mine ground control," International Journal of Mining Science and Technology, vol. 25, no. 1, pp. 1-6, 2015.

[4] A. J. S. Spearing, A. J. Hyett, T. Kostecki, and M. Gadde, "New technology for measuring the in situ performance of rock bolts," International Journal of Rock Mechanics and Mining Sciences, vol. 57, pp. 153-166, 2013. 
[5] M. Ghadimi, K. Shahriar, and H. Jalalifar, "Optimization of the fully grouted rock bolts for load transfer enhancement," International Journal of Mining Science and Technology, vol. 25, no. 5, pp. 707-712, 2015.

[6] C. R. Windsor and A. G. Thompson, "Rock reinforcementtechnology, testing, design and evaluation," Comprehensive Rock Engineering, vol. 4, pp. 451-484, 1993.

[7] I. W. Farmer, "Stress distribution along a resin grouted rock anchor," International Journal of Rock Mechanics and Mining Sciences \& Geomechanics Abstract, vol. 12, no. 11, pp. 347-351, 1975.

[8] A. Kilic, E. Yasar, and A. G. Celik, "Effect of grout properties on the pull-out load capacity of fully grouted rock bolt," Tunnelling and Underground Space Technology, vol. 17, no. 4, pp. 355-362, 2002.

[9] Y. Chen, "Experimental study and stress analysis of rock bolt anchorage performance," Journal of Rock Mechanics and Geotechnical Engineering, vol. 6, no. 5, pp. 428-437, 2014.

[10] J. Nemcik, S. Ma, N. Aziz, T. Ren, and X. Geng, "Numerical modelling of failure propagation in fully grouted rock bolts subjected to tensile load," International Journal of Rock Mechanics and Mining Sciences, vol. 71, pp. 293-300, 2014.

[11] A. Kilıc, E. Yasar, and C. D. Atis, "Effect of bar shape on the pull-out capacity of fully-grouted rockbolts," Tunnelling and Underground Space Technology, vol. 18, no. 1, pp. 1-6, 2002.

[12] S. Ma, J. Nemcik, and N. Aziz, "An analytical model of fully grouted rock bolts subjected to tensile load," Construction and Building Materials, vol. 49, pp. 519-526, 2013.

[13] T.-B. Zhao, W.-Y. Guo, Y.-C. Yin, and Y.-L. Tan, "Bolt pull-out tests of anchorage body under different loading rates," Shock and Vibration, vol. 2015, Article ID 121673, 8 pages, 2015.

[14] J. M. Hawkes and R. H. Evans, "Bond stresses in reinforced concrete columns and beams," Journal of the Institute of Structural Engineers, vol. 10, no. 24, pp. 323-327, 1951.

[15] L. He, X. M. An, and Z. Y. Zhao, "Fully grouted rock bolts: an analytical investigation," Rock Mechanics and Rock Engineering, vol. 48, no. 3, pp. 1181-1196, 2015.

[16] C. Li and B. Stillborg, "Analytical models for rock bolts," International Journal of Rock Mechanics and Mining Sciences, vol. 36, no. 8, pp. 1013-1029, 1999.

[17] L. Blanco Martín, M. Tijani, and F. Hadj-Hassen, "A new analytical solution to the mechanical behaviour of fully grouted rockbolts subjected to pull-out tests," Construction and Building Materials, vol. 25, no. 2, pp. 749-755, 2011.

[18] B. Benmokrane, A. Chennouf, and H. S. Mitri, "Laboratory evaluation of cement-based grouts and grouted rock anchors," International Journal of Rock Mechanics and Mining Sciences \& Geomechanics Abstracts, vol. 32, no. 7, pp. 633-642, 1995.

[19] F. F. Ren, Z. J. Yang, J. F. Chen, and W. W. Chen, "An analytical analysis of the full-range behaviour of grouted rockbolts based on a tri-linear bond-slip model," Construction and Building Materials, vol. 24, no. 3, pp. 361-370, 2010.

[20] C. C. Li, "A new energy-absorbing bolt for rock support in high stress rock masses," International Journal of Rock Mechanics and Mining Sciences, vol. 47, no. 3, pp. 396-404, 2010.

[21] A. J. Hyett, W. F. Bawden, G. R. Macsporran, and M. Moosavi, "A constitutive law for bond failure of fully-grouted cable bolts using a modified hoek cell," International Journal of Rock Mechanics and Mining Sciences and, vol. 32, no. 1, pp. 11-36, 1995.

[22] X. Feng, N. Zhang, and C. Lv, "Effects of interface damage resulting from the separation of layered strata on bolt anchoring systems," Shock and Vibration, vol. 2016, Article ID 2590816, 13 pages, 2016.

[23] A. J. Hyett, M. Moosavi, and W. F. Bawden, "Load distribution along fully grouted bolts, with emphasis on cable bolt reinforcement," International Journal for Numerical and Analytical Methods in Geomechanics, vol. 20, no. 7, pp. 517-544, 1996.

[24] C. C. Li, G. Stjern, and A. Myrvang, "A review on the performance of conventional and energy-absorbing rockbolts," Journal of Rock Mechanics and Geotechnical Engineering, vol. 6, no. 4, pp. 315-327, 2014. 


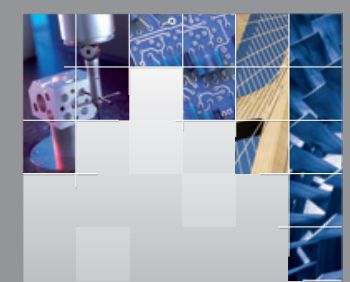

\section{Enfincering}
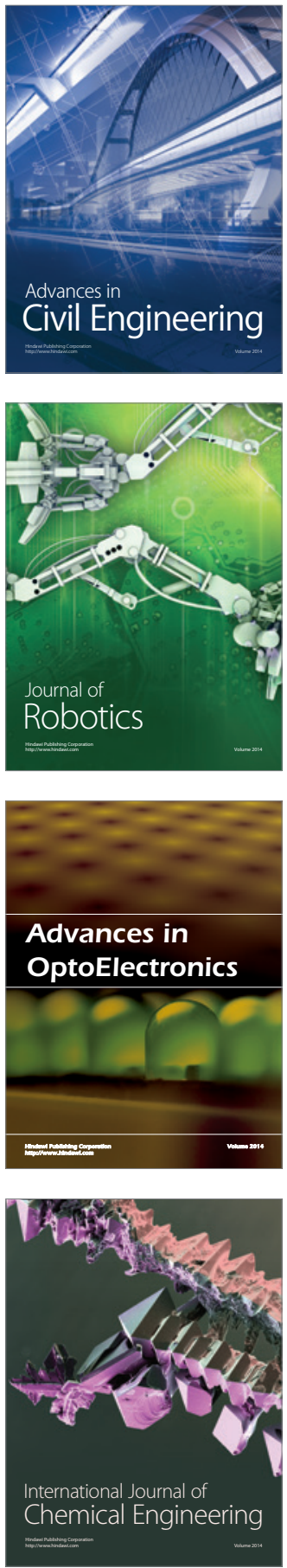

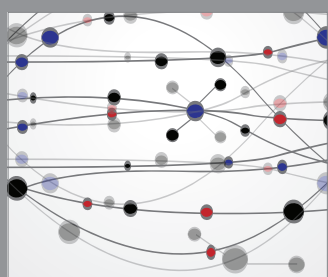

The Scientific World Journal

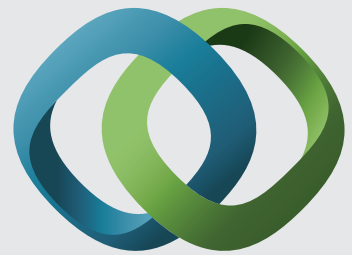

\section{Hindawi}

Submit your manuscripts at

https://www.hindawi.com
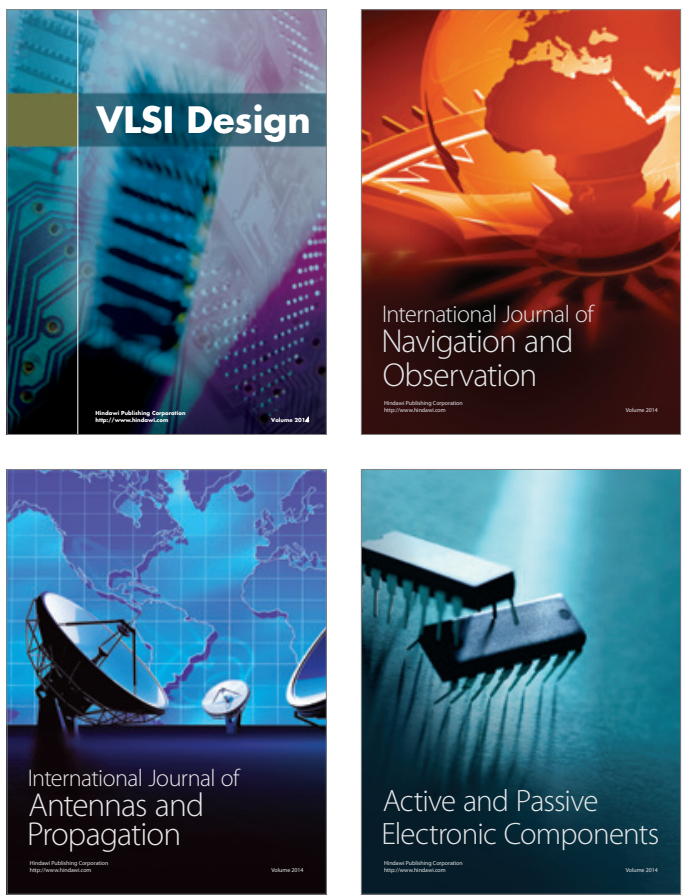
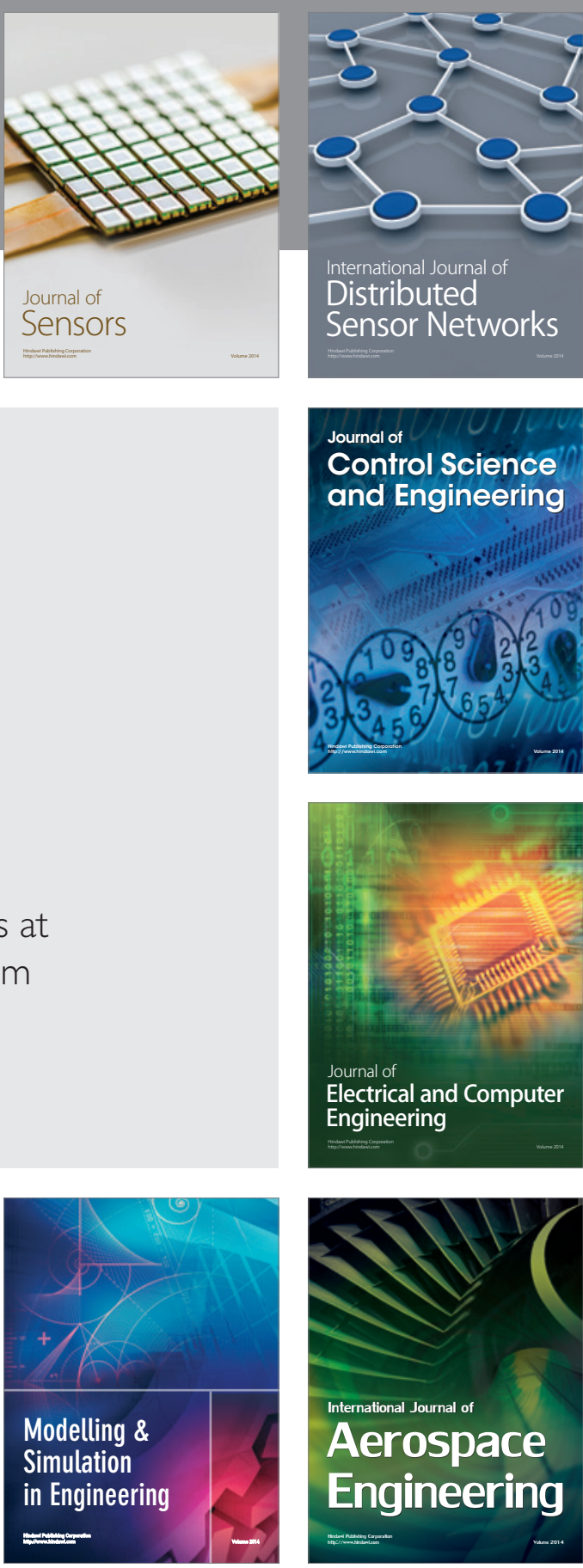

International Journal of

Distributed

Sensor Networks

$-$

Joumal of

Control Science

and Engineering
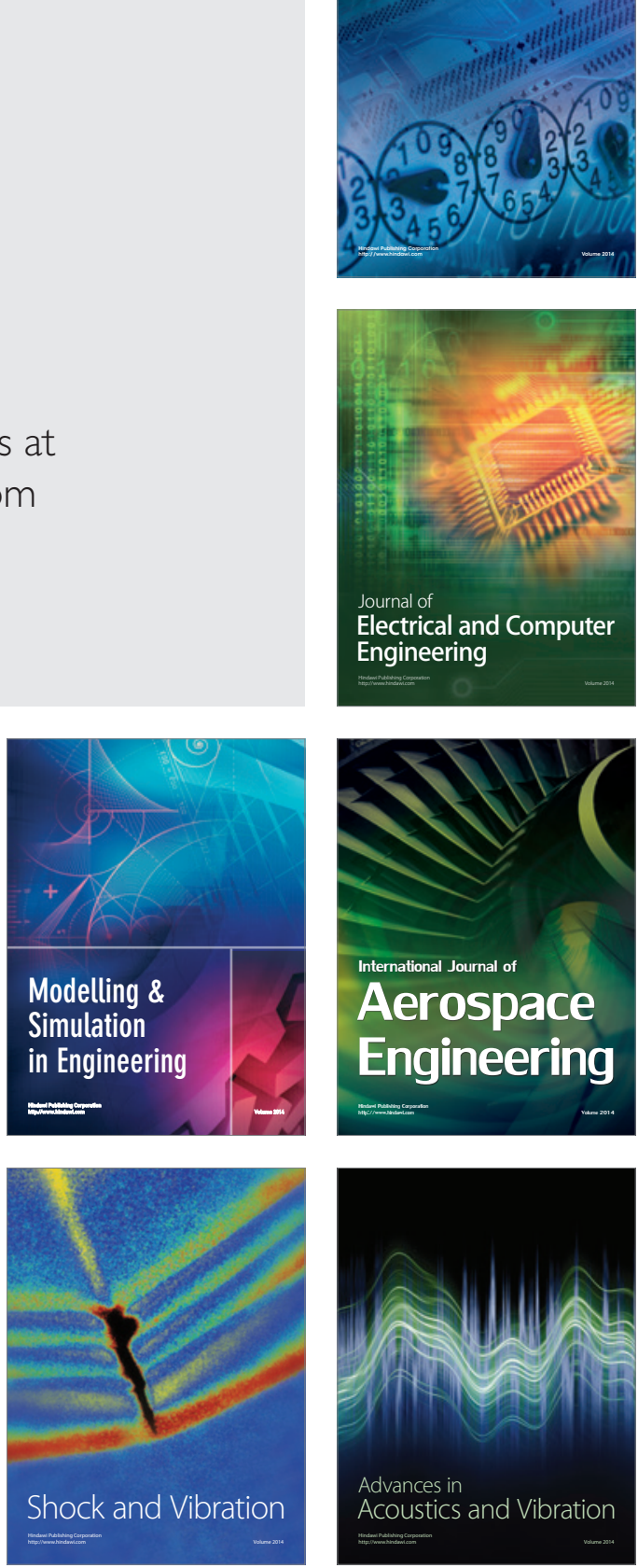